\title{
Organization of Olivocochlear Neurons in the Cat Studied with the Retrograde Tracer Cholera Toxin-B
}

\author{
W. Bruce Warr, ${ }^{1}$ Jo Ellen Beck Boche, ${ }^{1}$ Ye Ye, ${ }^{2}$ and D.O. Kim ${ }^{2}$ \\ ${ }^{1}$ Boys Town National Research Hospital, Omaha, NE 68131, USA \\ ${ }^{2}$ Department of Neuroscience, Division of Otolaryngology, Department of Surgery, University of Connecticut Health Center, \\ Farmington, CT 06030-3410, USA
}

Received: 21 September 2001; Accepted: 5 February 2002; Online publication: 9 April 2002

\section{ABSTRACT}

We employed cholera toxin-B (CTB), an efficient retrograde tracer, to examine olivocochlear (OC) neurons in the cat. Our primary goals were (1) to determine whether the cat has two types of lateral OC (LOC) neurons as is found in certain rodents and (2) to document the morphology, number, and caudorostral distribution of OC neurons, bilaterally. Adult cats received injections of CTB through the round window of the left cochlea, and, after 3-6 days, the brains were sectioned transversely and CTB was revealed immunocytochemically in every section. In three cats, OC neurons were mapped, counted differentially according to cell group, and the numbers of each plotted bilaterally from caudal to rostral. In one cat, measurements were made on labeled LOC and medial OC (MOC) neurons. The results indicate that LOC neurons can be divided into two groups based on their proximity to the lateral superior olive (LSO): a more populous group of small neurons that have intimate contact with the LSO, designated marginal-LOC neurons, and a less populous, morphologically heterogeneous group, lying more distantly from the LSO, designated para-LOC neurons. Para-LOC neurons lying dorsal and rostral to LSO were significantly larger than marginal-LOC. We hypothesize that the cat marginal-LOC neurons and most probably the larger para-LOC neurons correspond to rodent intrinsic and shell LOC neurons, respectively,

Correspondence to: W. Bruce Warr, Ph.D. - 555 N. 30th St., Boys Town National Research Hospital - Omaha, NE 68131. Telephone: (402) 498-6528; fax: (402) 498-6351; email: warr@boystown.org which have focal versus diffuse projections beneath the inner hair cells. Concerning MOC neurons, we confirm and extend previous observations on the clustering of these neurons near the rostral tip of the medial superior olivary nucleus and also show that MOC neurons differ in size according to cell group. Finally, we compare the present counts of OC neurons (mean total 1607, consisting of 1058 LOC neurons and 549 MOC neurons innervating one cochlea) and their proportional distribution ipsilaterally and contralaterally with those reported previously. Our estimate of the number of LOC neurons is somewhat higher than those previously obtained either by retrograde labeling with horseradish peroxidase or by counting unmyelinated axons in the olivocochlear bundle. In contrast, our estimate of the number of MOC neurons is very similar to those previously reported.

Keywords: cats, cochlea, cochlear efferents, olivocochlear, superior olive

\section{INTRODUCTION}

It is presently understood that the efferent innervation of the organ of Corti consists of two separate systems, lateral olivocochlear neurons (LOC) and medial olivocochlear neurons (MOC), that originate from neurons in lateral versus medial regions of the superior olivary complex (SOC) and that terminate, respectively, beneath inner (IHC) and outer hair cells (OHC) (for review see Warr 1992). This understanding is based largely, although not exclusively, on research in the cat. The innervation beneath the IHC 
is supplied mainly by small LOC neurons that are located in or around the lateral superior olivary nucleus (LSO) and that project by way of thin, unmyelinated axons predominantly to the ipsilateral cochlea. In contrast, the OHC innervation is supplied by large MOC neurons that are located in the medial periolivary region and that project by way of thick, myelinated axons predominantly to the contralateral cochlea (Warr 1975; Warr and Guinan 1979; Arnesen and Osen 1984, Brown 1987, 1993; Ryan et al. 1987; Wilson et al. 1991; Vetter and Mugnaini 1992; Warr et al. 1997; Horvath et al. 2000). Within the organ of Corti, the axons of LOC neurons synapse mainly with the dendrites of Type I ganglion cells beneath the IHCs (Smith 1961; Liberman 1980; Ginzberg and Morest 1984; Liberman et al. 1990; Satake and Liberman 1996), whereas the axons of MOC neurons synapse directly with the basolateral surface of the OHCs themselves (Kimura and Wersall 1962; Spoendlin 1966; Liberman et al. 1990).

There is clear morphological evidence, but so far only in rodents, that the efferent innervation beneath the IHCs is heterogeneous. Brown (1987) was the first to recognize that efferent fibers terminating beneath the IHC in the guinea pig were of two distinct types: more numerous $(84 \%)$ unidirectional axons and less numerous (16\%) bidirectional axons. Unidirectional axons coursed in the inner spiral bundle (ISB) less than $1 \mathrm{~mm}$ before terminating in relatively discrete clusters of terminals, whereas bidirectional fibers bifurcated into basal and apical branches that in toto could travel in the ISB and/or in the tunnel spiral bundle for up to $1.5 \mathrm{~mm}$.

Brown's (1987) discovery of two types of axons beneath the IHC clearly raises the question of the existence of two types of LOC neurons in the SOC. In what is perhaps the most definitive study to date, the efficient retrograde tracer, cholera toxin-B (CTB) (Ericson and Blomqvist 1988), was applied to the rat's cochlea with the result that LOC neurons were found to consist not only of numerous small "intrinsic" neurons within the LSO proper, but also of large stellate or "shell neurons," which were scattered about the margins of the LSO, mainly ipsilaterally (Vetter and Mugnaini 1992). These two cell types were also shown to be neurochemically distinct in that intrinsic neurons are immunoreactive to antibodies to calcitonin gene-related peptide (CGRP) and choline acetyltransferase (ChAT), whereas shell neurons are reactive only to ChAT (Kawai et al. 1985; Vetter et al. 1991), a pattern that appears to also pertain in the cat (Lu et al. 1987; Vincent and Reiner 1987).

Anterograde tracing studies in the rat (Warr et al. 1997) have shown that intrinsic LOC neurons (within the LSO) possess axons that enter the organ of Corti, travel short distances beneath the IHC, and terminate in discrete dense arbors. In contrast, shell LOC neurons have axons that bifurcate into basal and apical branches that, together, traveled long distances giving off sparse branches under the IHC. Although these two types of efferent fibers were morphologically very similar to the two fiber types described in the guinea pig (Brown 1987), Warr and his colleagues renamed them after their cells of origin, "intrinsic" and "shell" axons, respectively.

CTB was recently used to label olivocochlear (OC) neurons in the cat (Ye et al. 2000a). From these results it was seen that the labeling efficiency with CTB was noticeably higher than that of tracers employed previously in this species. Thus, such results were expected to serve as an improved basis for a systematic morphological analysis of various cell groups of OC neurons in the cat. Because this tracer was instrumental in the discovery of two types of LOC neurons in the rat (Vetter and Mugnaini 1992), we anticipated that it might also reveal a homologous condition in the cat. We present results here that address this question and, more generally, results that characterize the number, distribution, and morphology of LOC and MOC neurons in the cat more fully than previously available. Early results of the present study were reported at scientific meetings (Warr et al. 2000, 2001).

\section{MATERIALS AND METHODS}

The present study was conducted in both Farmington, CT, and Omaha, NE. The handling of the animals and the production of histological slides were conducted in Farmington and microscopic examination and analysis were conducted mostly in Omaha.

\section{Animals and surgery}

The animal and histological procedures used in this study were essentially the same as those of Ye et al. (2000a). These procedures followed the Public Health Service Policy on Humane Care and Use of Laboratory Animals and were approved by the Animal Care Committee, University of Connecticut Health Center. Four pigmented, female, domestic cats weighing $2.0-3.5 \mathrm{~kg}$ were used in this study. The animals were purchased from a commercial breeder and had clean external ear canals and no history of disease or hereditary abnormalities. Each cat was initially anesthetized with an intraperitoneal injection of sodium pentobarbital, $35 \mathrm{mg} / \mathrm{kg}$. An intravenous catheter was installed and deep anesthesia was maintained by administering sodium pentobarbital through the catheter. Animal body temperature was maintained near $38^{\circ} \mathrm{C}$. 
Using sterile procedures, the bulla was opened and CTB (List Biological Laboratories, Inc., Campbell, CA) $(8-10 \mu \mathrm{l}, 1 \%)$ was injected into scala tympani of the left cochlea through a micropipette (inner diameter $\sim 30 \mu \mathrm{m}$ ) which penetrated the round window membrane. Injection of CTB was made using several pulses (typically $25 \mathrm{psi}, 50 \mathrm{~ms}$ pulse duration, over a period of about $20 \mathrm{~min}$ ) from a pressure injector (Picospritzer, General Valve Corp., East Hanover, $\mathrm{NJ}$ ). Upon withdrawal of the micropipette, the round window membrane showed no detectable signs of fluid leakage.

\section{Fixation and histology}

After a survival period of 3-6 days, cats were anesthetized as above and perfused transcardially, initially with saline and subsequently with a solution containing $4 \%$ paraformaldehyde, $0.1 \%$ glutaraldehyde in $0.1 \mathrm{M}$ sodium phosphate-buffered saline (PBS), $\mathrm{pH}$ 7.4 , at room temperature. The brain tissue was kept in $30 \%$ sucrose for 1 day. Frozen sections were cut at 50 $\mu \mathrm{m}$ in the transverse plane. To demonstrate CTB immunoreactivity, all sections were first incubated for $2 \mathrm{~h}$ at room temperature in 5\% normal horse serum (Jackson Immuno Research Laboratories, Inc., West Grove, PA), followed by primary antibody (goat antiCTB, List Biological Laboratories, Inc., Campbell, $\mathrm{CA} ; 1: 20,000)$, at $4^{\circ} \mathrm{C}$, under agitation for $1-2$ days. The sections were then rinsed and incubated with a secondary antibody (biotinylated antigoat IgG, made in horse, Vector Laboratories Inc., Burlingame, CA; $1: 2,000)$ in $0.1 \mathrm{M}$ PBS, overnight, $4^{\circ} \mathrm{C}$ under agitation. The sections were incubated in $\mathrm{ABC}$ overnight at $4^{\circ} \mathrm{C}$ and treated with diaminobenzidine with metal intensification (Adams 1981). Either all or alternate sections were counterstained with cresyl violet.

In addition to the experimental cats, several other sets of serial sections of the cats' brainstems were available for reference. These included one control animal in which stapedial motoneurons on the left side were retrogradely labeled with horseradish peroxidase (HRP) which was used to assess whether any stapedial neurons were inadvertently labeled in the experimental series. Several brains sectioned in one of the three cardinal planes and stained alternately with Protargol (Bodian 1936) or cresyl violet were available, as were several others sectioned in the transverse plane and stained for acetylcholinesterase (Mathisen and Blackstad 1964) and counterstained with cresyl violet.

\section{Imaging, cell counting, and measurement}

Using a Zeiss Standard microscope, low-power and high-power color images of retrogradely labeled cells from at least 20 levels, ipsilaterally and contralaterally, throughout the brainstem (cats Q86 and Q104) were captured using a Spot Digital Camera (Diagnostic Instruments, Inc.). Images were printed and used to compare the labeling on the two sides, between animals, as well as to select material for drawings and higher-magnification digital imaging.

OC neurons were classified as either LOC or MOC according to their location lateral or medial, respectively, to an imaginary partition passing through the center of each medial superior olivary nucleus (MSO) and extending both dorsoventrally and rostrocaudally into the surrounding periolivary region (Guinan et al. 1983).

LOC neurons were classified as marginal-LOC if they were located in the dorsal hilus of the lateral superior olive (LSO) or within or on the margins of the nucleus itself (Figs. 2 and 3). Neurons were classified as para-LOC if they were located beyond the margins of the LSO in one of three periolivary regions surrounding the LSO, specifically the dorsolateral periolivary area (DLPO), the lateral nucleus of the trapezoid body (LNTB), or the anterolateral periolivary area (ALPO). We have adopted the definition of the LNTB given by Spirou and Berrebi (1996) whereby this nucleus lies not only beneath the LSO, but also extends approximately $300-400 \mu \mathrm{m}$ rostral to it. The DLPO includes the entire periolivary region dorsal to the LSO and thus includes neurons that others have designated the mediodorsal periolivary area (Osen et al. 1984; Thompson 1998, Spirou and Berrebi 1996). We also defined ALPO similarly to Spirou and Berrebi (1996) as a rostral extension of DLPO that curves ventrally around the rostral aspect of the LSO where it meets LNTB (Fig. 1E, left).

MOC neurons in the ventral nucleus of the trapezoid body (VNTB) or in the territories of the dorsomedial periolivary nucleus and the medial nucleus of the trapezoid body (DMPO/MNTB) were counted separately (Fig. 1A-F). At rostral levels of the SOC where the MNTB was not present, we continued to arbitrarily distinguish two medial regions, the dorsal half of which we label DMPO and the ventral half of which we label VNTB, as shown in Figure 1H and I (right). For purposes of analysis, labeled DMPO cells at this level were pooled with those more caudally in DMPO/MNTB.

In order to be included in the present analysis, we required that the brainstem be free of labeled stapedial motoneurons, because some of these cells intermingle with OC neurons in the ipsilateral DLPO (Shaw and Baker 1983; Joseph et al. 1985). Three of the four cats met this criterion (Q86, Q100, and Q104).

Counts of all labeled OC neurons were made bilaterally in serial sections in each of the six perioli- 
Cat \#Q104
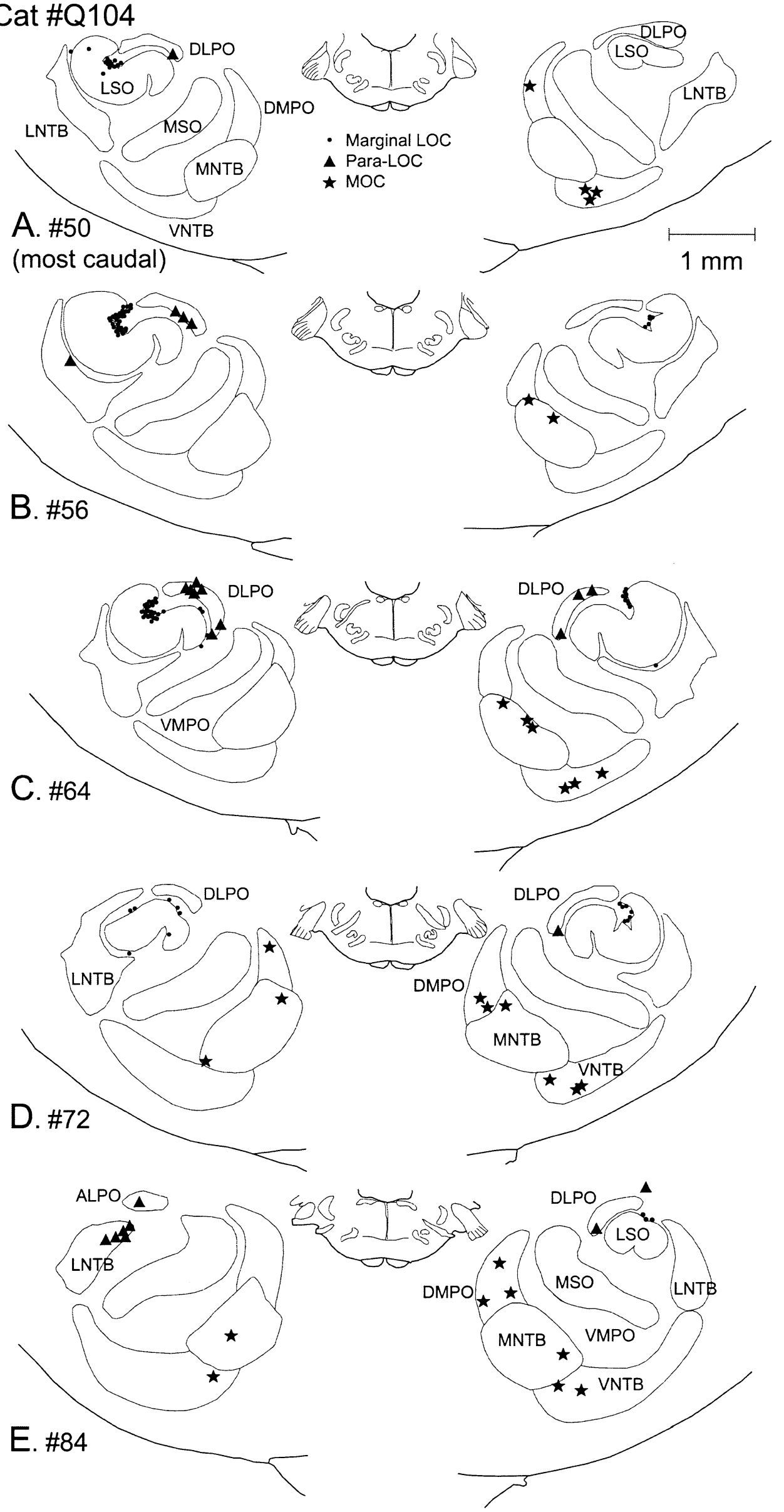

FIG. 1. continued 

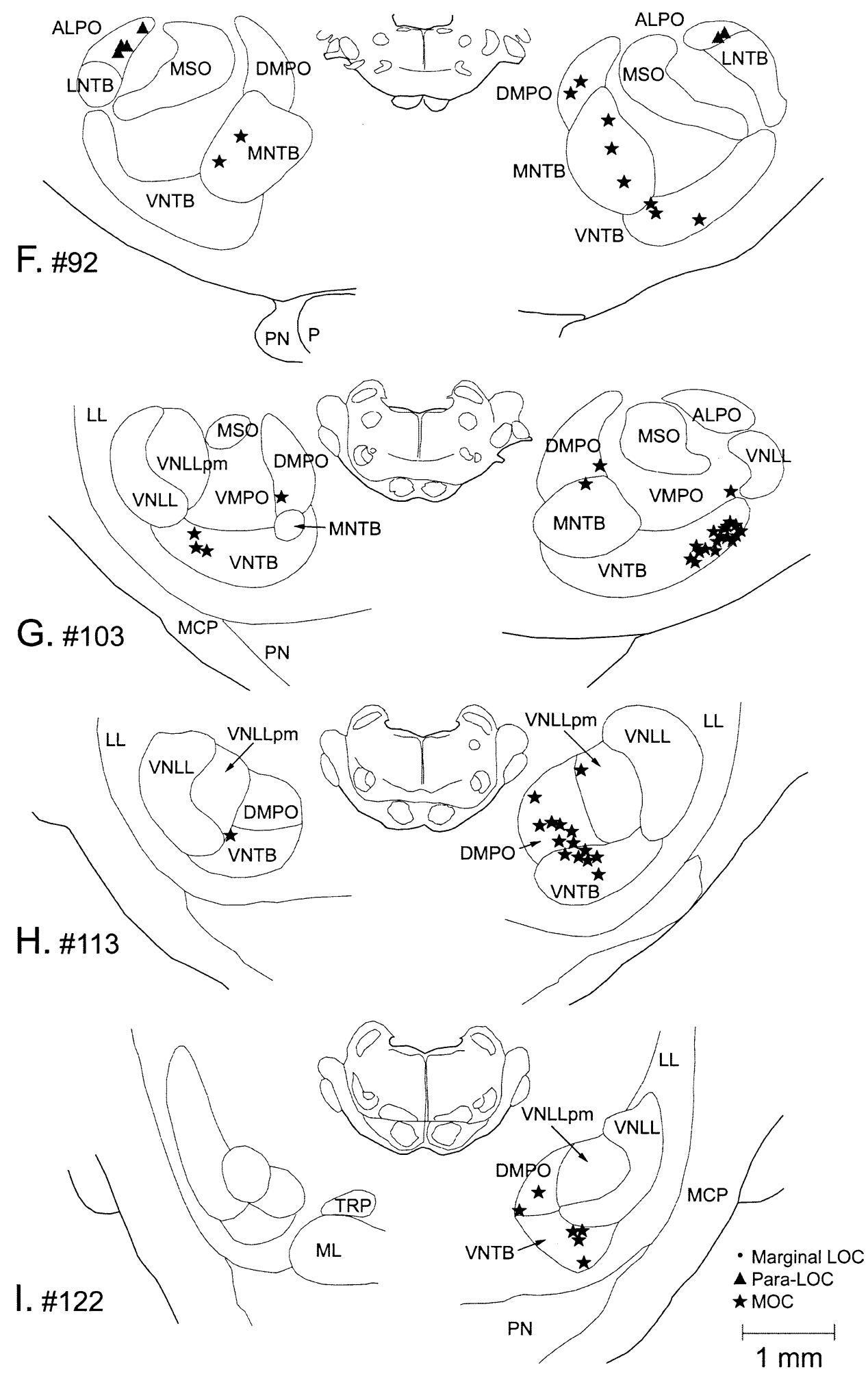

FIG. 1. A-I. Series of projection drawings of cresyl violet counterstained sections at nine levels of the SOC showing the locations of labeled olivocochlear neurons in cat Q104 following injection of CTB into the left cochlea. The three types of OC neurons are represented by different symbols (see key in A). Each symbol represents one cell, except where prevented by crowding. The number of neurons plotted in each region was equal to at least the mean of the counts in that section and in the two adjacent sections. A slight asymmetry exists in the plane of sectioning such that the left side is more rostral than the right by approximately $300 \mu \mathrm{m}$. Abbreviations: ALPO, anterolateral periolivary area; DMPO, dorsomedial periolivary area; DLPO, dorsolateral periolivary area; LL, lateral lemniscus; LNTB, lateral nucleus of the trapezoid body; LSO, lateral superior olive; $\mathrm{MCP}$, middle cerebellar peduncle; $M L$, medial lemniscus; MNTB, medial nucleus of the trapezoid body; MSO, medial superior olive; $\mathrm{P}$, pyramid; $\mathrm{PN}$, pontine nucleus, TRP, tegmental reticular nucleus, pericentral division; VMPO, ventromedial periolivary area; VNLL, ventral nucleus of the lateral lemniscus; VNLLpm, posteromedial region of VNLL; VNTB, ventral nucleus of the trapezoid body.

vary regions defined above. Because of their small size and tendency to form clusters, LOC neurons were counted mainly with a $25 \times$ objective, but occasionally a $40 \times$ oil immersion objective was required to resolve clusters. MOC neurons, being larger and more scattered, were typically counted using a $10 \times$ or a $16 \times$ objective. To control overestimating cellular populations from histological preparations (Coggeshall and Lekan 1996), we assigned a value of 1.0 to a labeled cell only when, by "through-focusing," it appeared that the majority of the soma was contained within the depth of the 

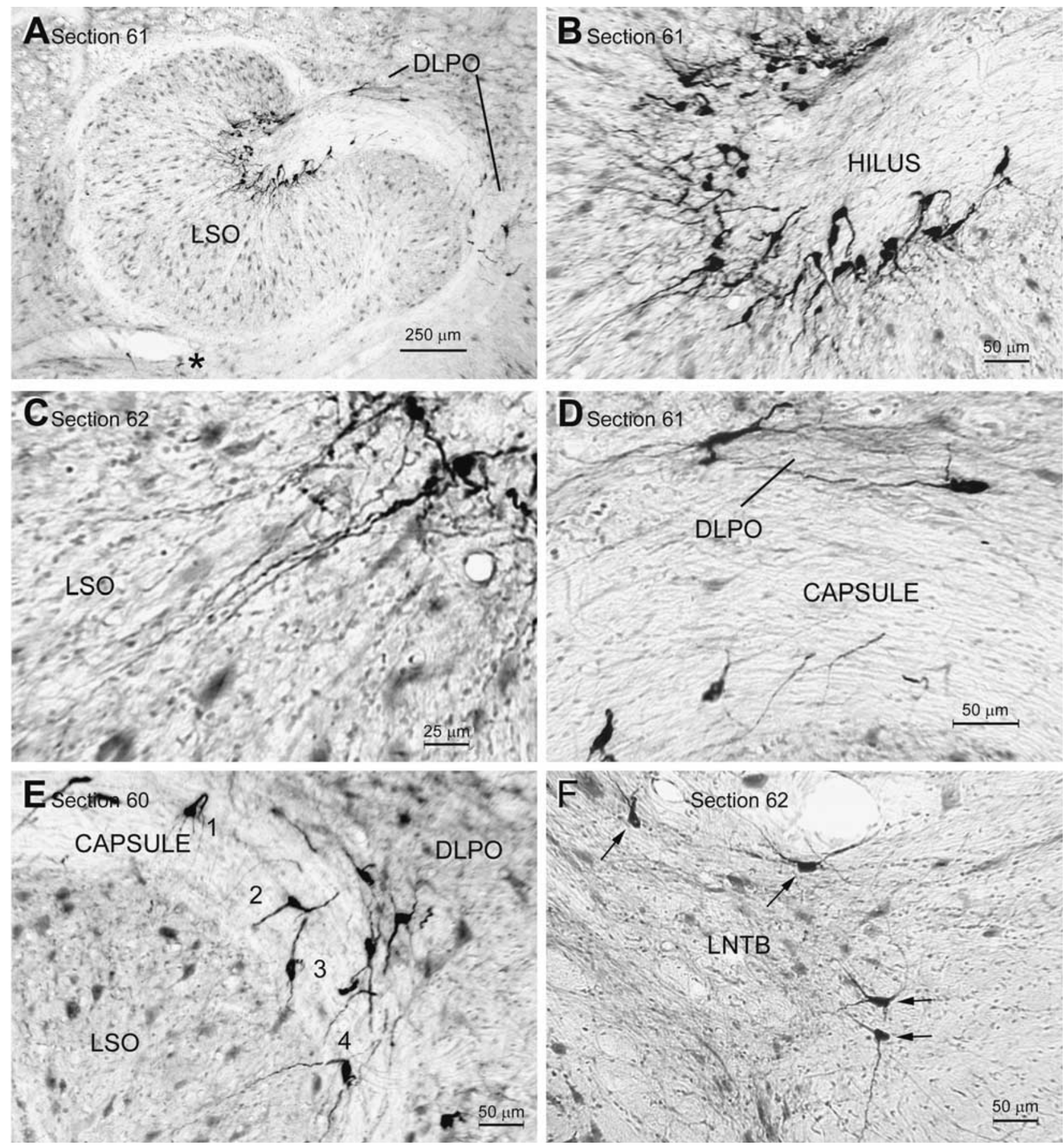

FIG. 2. Labeled LOC neurons near the ipsilateral LSO in sections 60-62 of cat Q104 (see Fig. 1C for comparable level). A. Numerous marginal-LOC neurons line the dorsal hilus of the LSO. Several paraLOC neurons are scattered in the DLPO dorsal and medial to the LSO. Asterisk indicates the position of labeled neurons in F. B. Marginal-LOC neurons shown in A exhibit a range of sizes and shapes but virtually all send a dendrite into the LSO neuropil. Note the absence of labeled dendrites within the dorsal hilus. C. Several dendrites belonging to marginal-LOC in the dorsal hilus are shown extending ventrolaterally, parallel to the isofrequency laminae of the

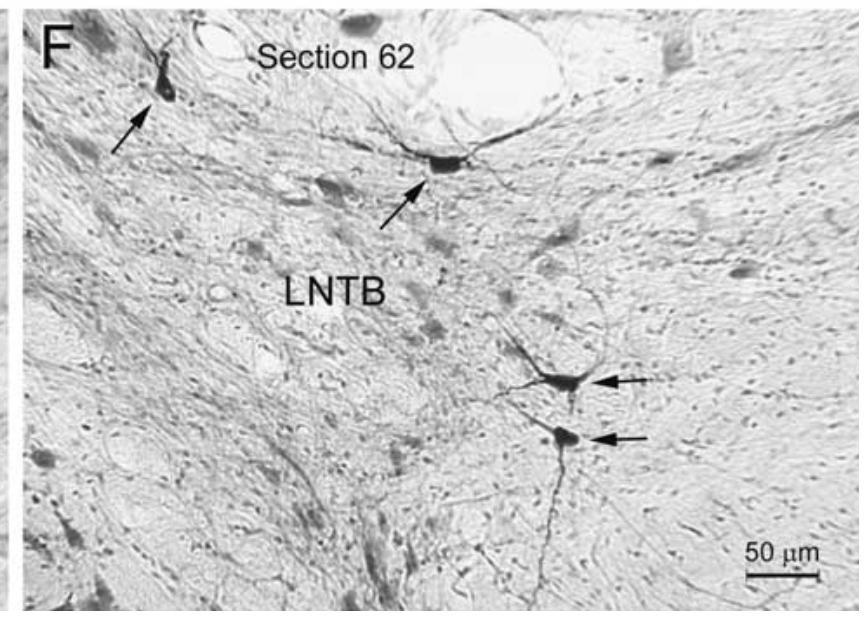

LSO. D. Para-LOC neurons in DLPO (top) exhibiting a fusiform shape and long dendrites oriented parallel to the subadjacent fiber capsule of the LSO. The two labeled neurons at the lower left were classified as marginal-LOC. E. Distinction between marginal- and para-LOC in capsule of LSO was made on the basis of proximity to the LSO. Cells labeled 1 and 2 were classified as para-LOC and cells labeled 3 and 4 were classified as marginal-LOC. F. Four para-LOC neurons (arrows) near the medial margin of LNTB (location relative to LSO shown by asterisk in A). All sections in this figure and Figures 3 and 4 were counterstained with cresyl violet. 

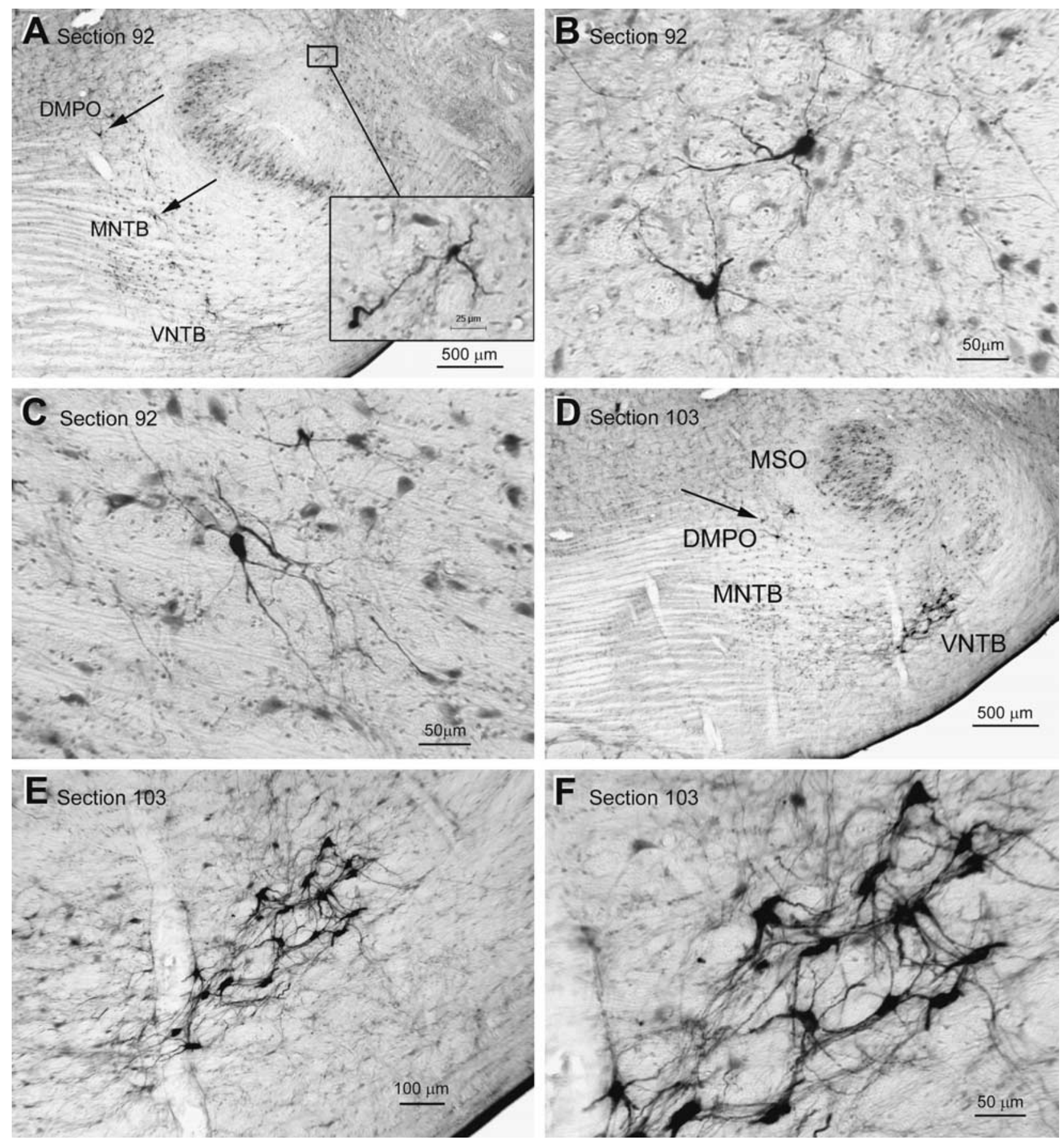

FIG. 4. Examples of labeled MOC and LOC neurons in the contralateral SOC of sections 92 and 103 of cat Q104 (refer to Fig. 1F, G for delineation of nuclei). A. Survey view showing locations of MOC cells in DMPO and MNTB (arrows) and para-LOC neurons in ALPO immediately adjacent to the rostral LSO (box). Inset shows details of two neurons in ALPO. B. Higher-magnification view of MOC neurons in DMPO illustrating their large tapering dendrites. C. Higher-magnification view of MOC cell in MNTB with two dendrites extending

section. In cases where it appeared that a cell had been bisected into two approximately equal halves, the cell was assigned a value of 0.5 .

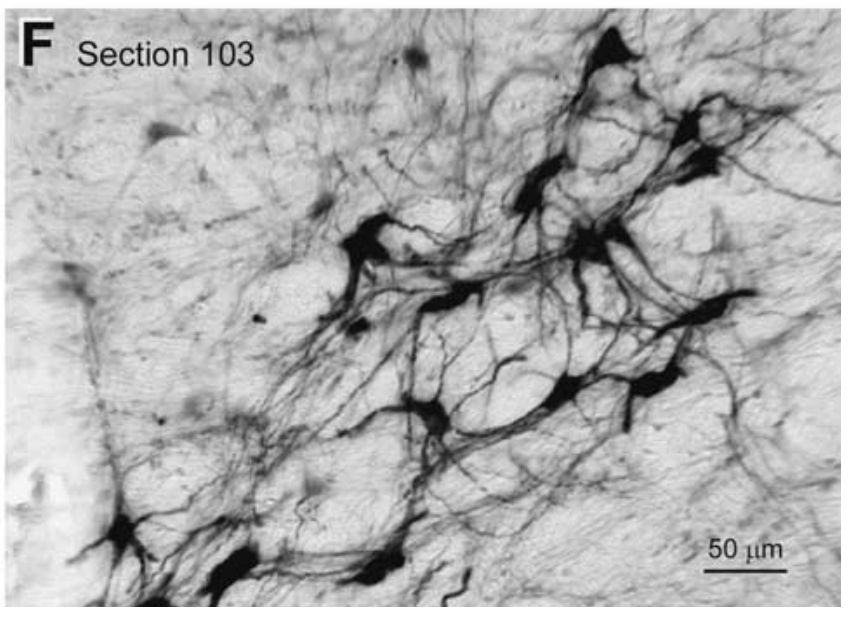

ventrolaterally. The thick dendrite to the right of the labeled cell belongs to a neuron whose soma is located in section 91. D. Lowmagnification view of Section 103 showing location of MOC neurons in DMPO (arrow) and the large cluster of these cells in VNTB. E. Higher-magnification view of MOC neurons in VNTB illustrating the orientation of these cells primarily parallel with the ventral acoustic stria. F. High-magnification view of MOC neurons in VNTB showing the of fasciculation and interweaving of dendritic arbors.

In one animal (Q104), measurements of soma area and shape were made on approximately 20 labeled OC neurons in each of the six periolivary zones. All 

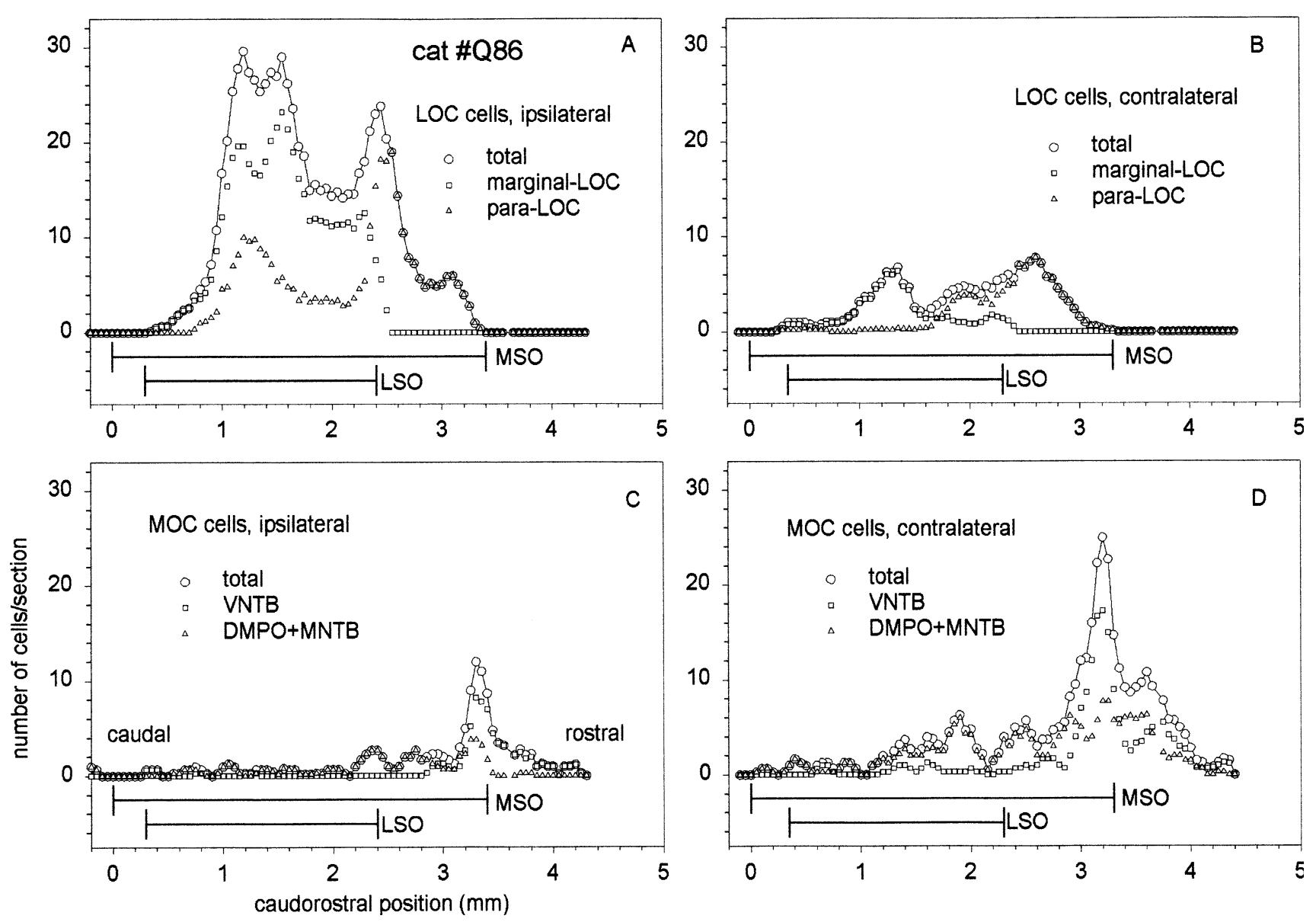

FIG. 5. Caudorostral distributions of cell density of ipsilateral and contralateral LOC (A,B) and MOC neurons (C, D) in cat Q86. Zero on the abscissa corresponds to the caudal end of the MSO. The longitudinal extents of both the LSO and MSO are indicated on each panel. LOC and MOC neurons are divided into subgroups; see key to symbols on each panel. In A and B, the number of para-LOC neurons

labeled somata within a given tissue section were measured if they met two criteria: (1) the soma was fully contained within the depth of the $50 \mu \mathrm{m}$ tissue section and (2) at least two dendrites were visible. Because of the small number of labeled cells present in one periolivary region (ALPO), only 14 cells meeting these criteria could be found. Cells were imaged with a Zeiss $40 \times$ planapochromatic oil immersion objective and the perimeter of the soma, not including the dendrites, was manually traced with the mouse using ImagePro. The program then calculated the area as well as the length of the major and minor axes, which pass through the center of the cell area or centroid. The data were imported into Excel (Microsoft) and $p$-values of two-tailed $t$-tests between the several populations were determined. Because performing multiple $t$-tests on the same set of data increases the probability of erroneously rejecting the null hypothesis, we adjusted the $p$-value required for significance to 0.005 (Bonferroni correction).

corresponds to all para-LOC neurons in DLPO, LNTB, and ALPO. Five-point moving-window averaging was used for $A$ and $B$ in this figure and all other panels of Figures 8 and 9 . For $C$ and D of this figure, 3-point moving-window averaging was used because it preserved the peaks better in these data.

\section{RESULTS}

\section{Initial comments and considerations}

In all four cats, retrograde labeling obtained with CTB consisted of a dense, black or brown reaction product that appeared to evenly fill the somata and dendrites, but not the nucleus, of neurons located in regions known to project either to the cochlea (Warr 1975; Warr et al. 1986; Adams 1983) or to the vestibular labyrinth (Gacek and Lyons 1974; Ito et al. 1983; Dechesne et al. 1984). We also observed anterograde CTB labeling of cochlear nerve terminals ipsilateral to the injection (Vetter and Mugnaini 1992; Ye et al. 2000b). The fact that this labeling extended over the full dorsoventral extent of the ventral cochlear nucleus (VCN) was taken as an indication that CTB had reached the entire length of the cochlea (Sando 1965). In order to exclude labeled vestibular efferent neurons from being counted, we considered OC neurons to be only those within 

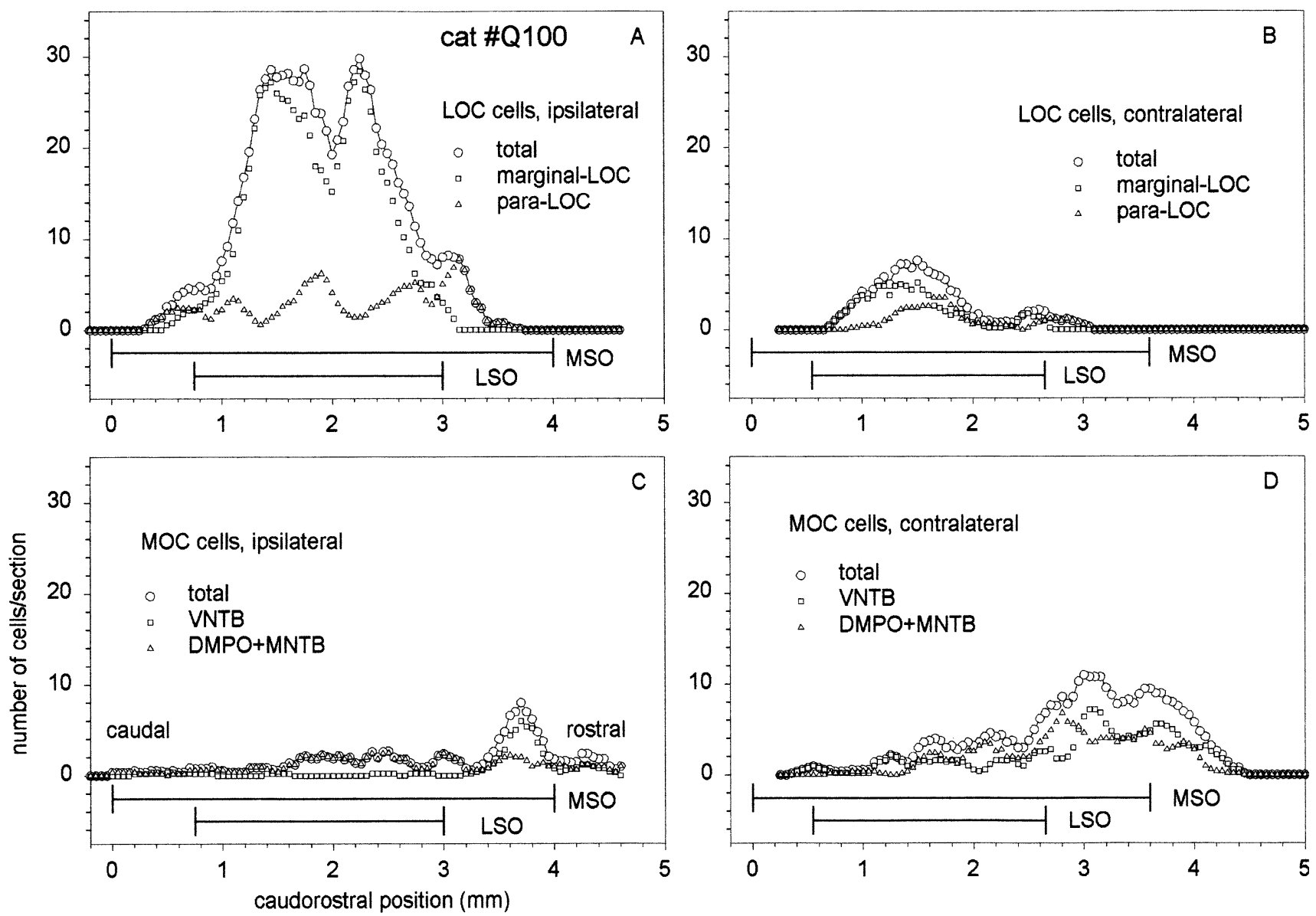

FIG. 6. Caudorostral distributions of cell density of ipsilateral and contralateral LOC (A, B) and MOC neurons (C, D) in cat Q100. See the caption of Figure 5 for details.

the confines of the SOC, as defined above and delineated in Figure 1.

\section{Location of OC neurons}

Mapping labeled OC neurons in Q104. Figure 1 provides an overview of the location and number of labeled LOC and MOC neurons found in one representative cat (Q104). Regarding LOC, inspection of the entire lateral region of the SOC on the ipsilateral side shows that marginal-LOC neurons (dots) comprise a dense population immediately adjacent to and in the LSO and that para-LOC (triangles) are also present in the cell groups surrounding the LSO, including DLPO, LNTB, and ALPO, but in much fewer numbers than marginal-LOC neurons (Fig. 1A-F). Contralaterally, a similar relationship exists although the numbers of both marginal-LOC and para-LOC neurons are fewer. It is notable that there were virtually no para-LOC in the contralateral LNTB. Regarding MOC neurons, inspection of the entire longitudinal extent of the medial region of the SOC shows that MOC neurons (stars) form an irregular arc extending from DMPO and MNTB to VNTB, but labeling is virtually absent from the ventromedial periolivary group (VMPO), which has been shown to contain large neurons projecting to the ipsilateral inferior colliculus (Adams 1983). MOC neurons are more numerous contralaterally than ipsilaterally and are also more numerous rostrally than caudally. A major cluster of MOC neurons occurs in VNTB near the rostral end of the contralateral MSO (Fig. 1G, H).

Examples of labeled LOC neurons in Q104. Images illustrating the general morphology and locations of LOC and MOC neurons are presented in Figures 2-4. More detailed morphometric date are presented in the final section of the Results (Figs. 8 and 9).

Figure 2A shows a cross section through the ipsilateral LSO containing numerous marginal-LOC neurons and a smaller number of para-LOC neurons within the DLPO. Most marginal-LOC neurons are located within the dorsal hilus of the LSO, whereas far fewer are found along the medial, high-frequency lobe of the nucleus. Less commonly, marginal-LOC somata appear to be fully contained within the neuropil of the LSO proper (Fig. 2B). The somata of 

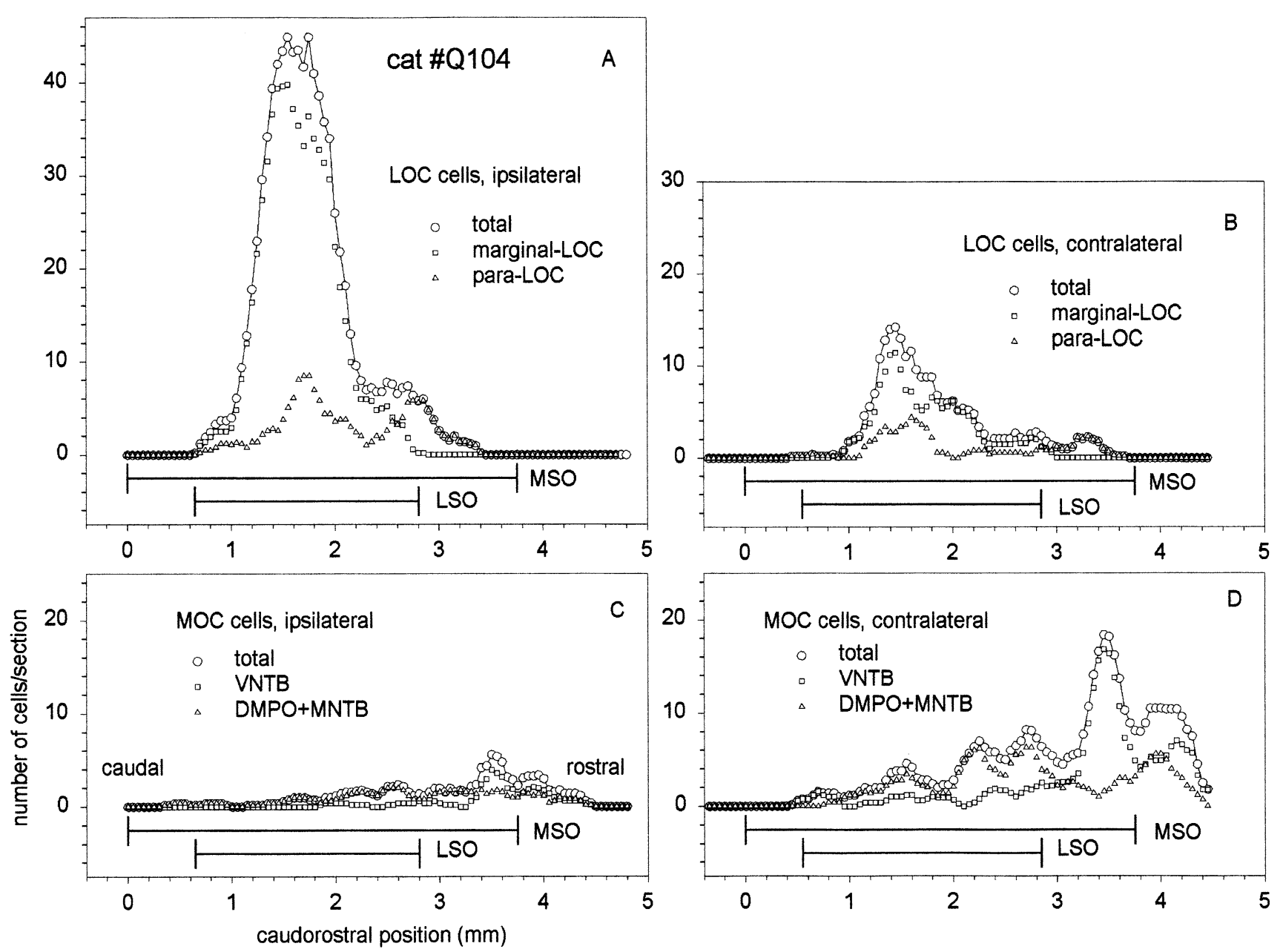

FIG. 7. Caudorostral distributions of cell density of ipsilateral and contralateral LOC (A, B) and MOC neurons (C, D) in cat Q104. See the caption of Figure 5 for details.

marginal-LOC neurons exhibit a somewhat narrow range of sizes and shapes (Fig. 2B), and virtually all were observed to send at least one, and often two, of their slender dendrites at least half way across the LSO (Fig. 2C), parallel to the isofrequency planes of this nucleus (Tsuchitani and Boudreau 1966). By through focusing with a $100 \times$ oil immersion objective, dendritic profiles belonging to marginal-LOC neurons could also be observed extending caudorostrally in close apposition with the contour of the LSO (not shown), which confirms Adams' (1983) observation in sagittal sections that dendrites of these cells exhibit two principal orientations, rostrocaudal and parallel to the isofrequency planes of the LSO. We did not observe dendrites extending into the hilus or fiber capsule surrounding the LSO, otherwise they would have been filled with labeled elements, contrary to what is visible (Fig. 2B, D).

Labeled para-LOC neurons exhibit somewhat different morphologies depending upon their location. In DLPO, which in two of the three cats (Q100 and
Q104) was the largest single source of para-LOC neurons, cells were often relatively large, fusiform, and had long dendrites oriented parallel to the adjacent LSO (Fig. 2D). However, DLPO also included small multipolar cells which, in some cases, sent one or more dendrites toward the LSO (Fig. 2E, cells 2 and 3). Among the largest para-LOC neurons were those in the most medial part of DLPO bilaterally (Figs. 2A and 3A).

Labeled neurons in LNTB (Fig. 2F, arrows) were more similar in size and shape to marginal-LOC neurons than they were to those in either DLPO or ALPO. Typically these small fusiform cells were situated along the edges of the main cellular mass of the LNTB rather than centrally within it.

In ALPO (Fig. 3D-F, Fig. 4A), which has been described as a rostral extension of DLPO (Spirou and Berrebi 1996), labeled neurons were nearly as large as those in DLPO and often formed clusters of 3-5 cells, the somata and dendrites of which were oriented from dorsomedial to ventrolateral, approximately 
TABLE 1

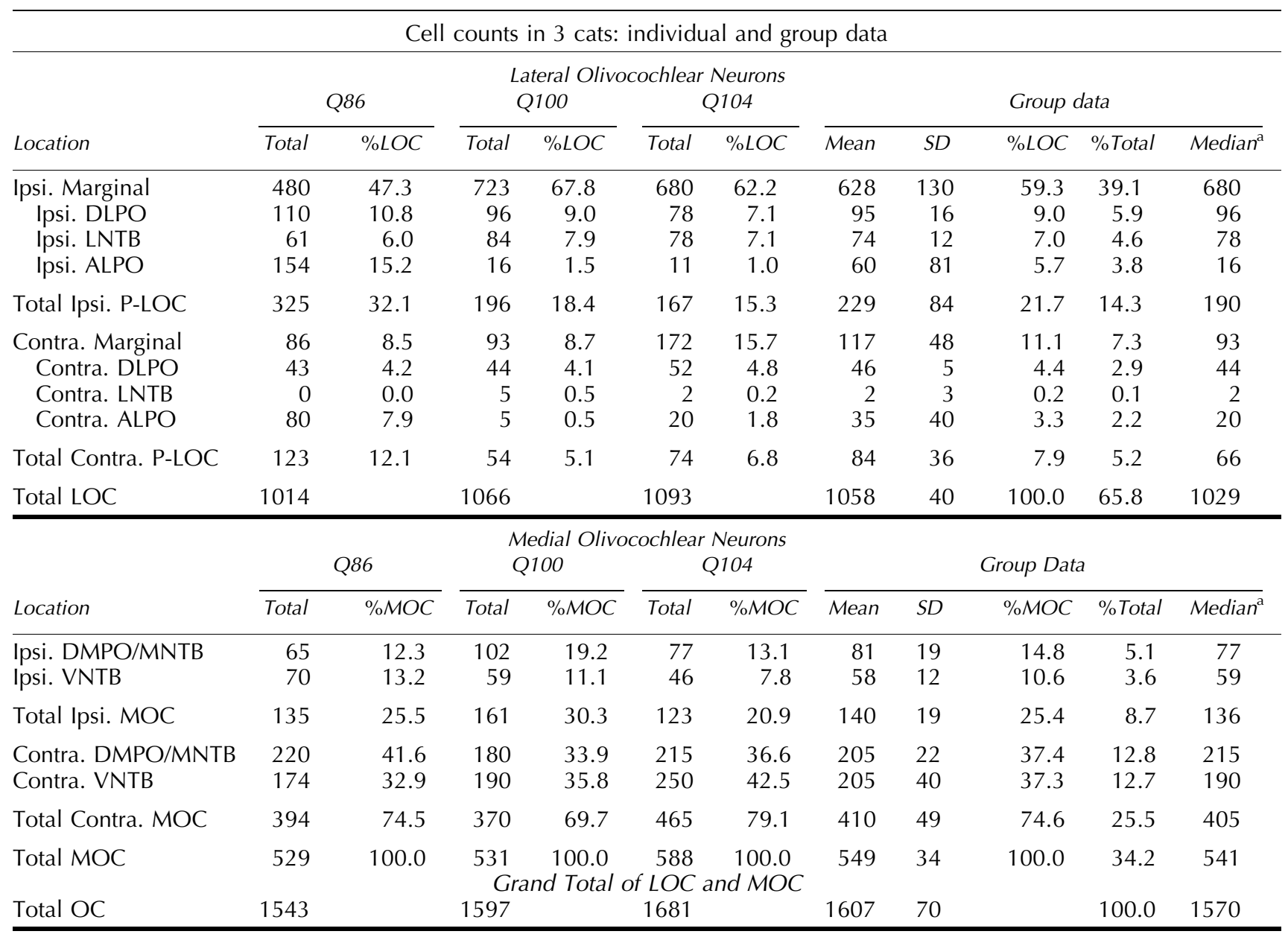

\footnotetext{
${ }^{\mathrm{a}}$ The median value for each subgroup is the intermediate value among the three cats. The median total of a group, e.g., P-LOC, MOC, or the grand total at the lower right corner (1570), was the sum of the medians comprising the group rather than the median value among the three cats (1597).
}

parallel to the axon collaterals arising from the underlying ventral acoustic stria.

Examples of labeled MOC neurons in Q104. The region shown in Figure $4 \mathrm{~A}$ is adjacent to the rostral end of the LSO but caudal to the peak in MOC neuron density that occurs near the rostral end of the MSO (see Fig. 1F for delineation of SOC nuclei shown in Fig. 4A). Arrows in Figure 4A indicate the locations of labeled MOC cells in DMPO and MNTB that are imaged at higher magnification in Figure $4 \mathrm{~B}$ and $\mathrm{C}$. These cells exhibit, to a greater or lesser degree, certain common features of MOC neurons in that they have large, tapering, branched dendrites that, after their first bifurcation, usually curve gradually out of the plane of section. Because of this curving of secondary dendrites, it was rare to be able to trace the MOC dendrites more than a few cell diameters away from the soma in $50 \mu \mathrm{m}$ thick sections. The labeled cell in Figure 4C has two dendrites that can be followed for considerable distances as they extend ven- trolaterally, parallel to axis of the MSO (shown at center right in Fig. 4A).

Figure $4 \mathrm{D}-\mathrm{F}$ shows examples of labeling at the level of the cluster of MOC neurons in the contralateral VNTB (see Fig. 1G for delineation of nuclei in Fig. 4D). The higher-magnification images (Fig. 4E, F) illustrate the cluster's flattened ovoid profile, the orientation of primary dendrites, as well as the extensive fasciculation of secondary dendrites. The principal orientation of the primary dendrites and dendritic fascicles is similar to that of the neuronal cluster itself, namely ventromedial to dorsolateral, although a few exceptional dendrites extend ventrolaterally, thus traversing the ventral acoustic stria, in which the VNTB itself is embedded (Fig. 4E, F).

\section{Longitudinal distribution of OC neurons}

In order to investigate the caudorostral distributions of LOC and MOC neurons, we separately plotted 


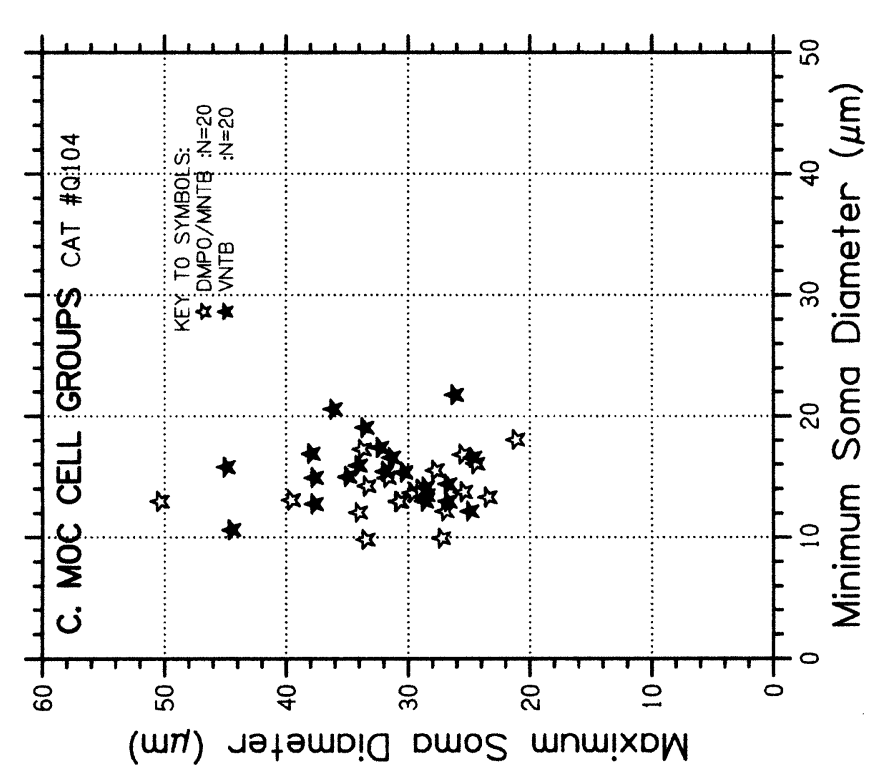

$\frac{0}{3} \frac{d}{\frac{d}{0}}$

$\overline{\bar{\theta}} \stackrel{0}{ }$

U =

$\times$

$\stackrel{0}{ \pm}$

$\varepsilon$ 次

O)

ㅇํㅇ ह

을

(wr) ләғәسD! Dwos wnw!XDW

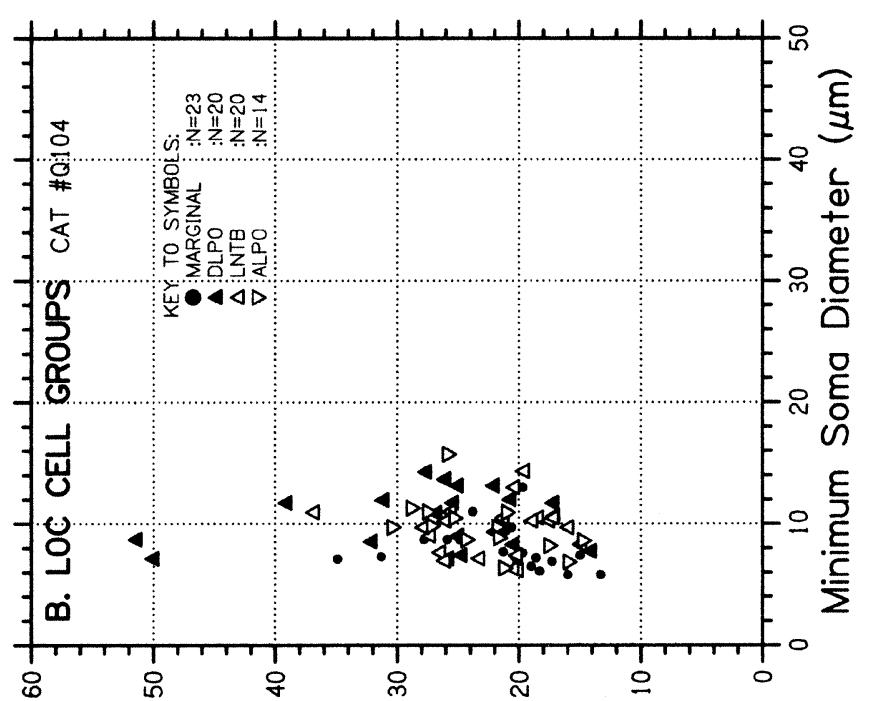

党

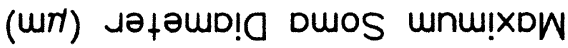

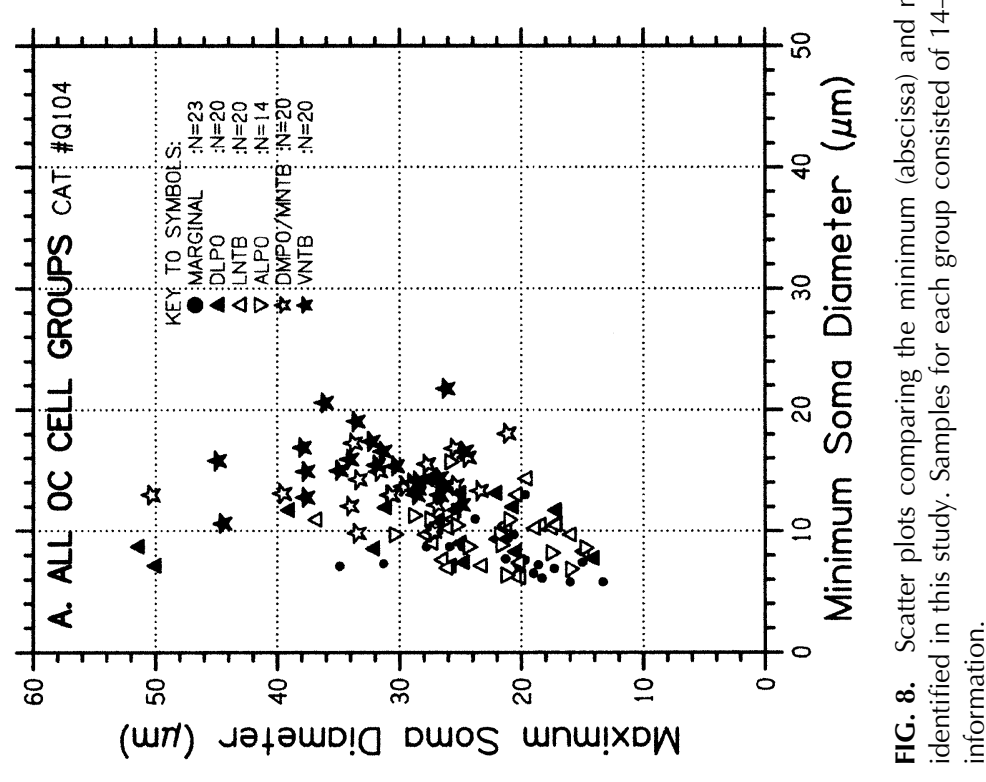




\section{A. Graphic Representation of Mean Cell Body Dimensions and their Variability}

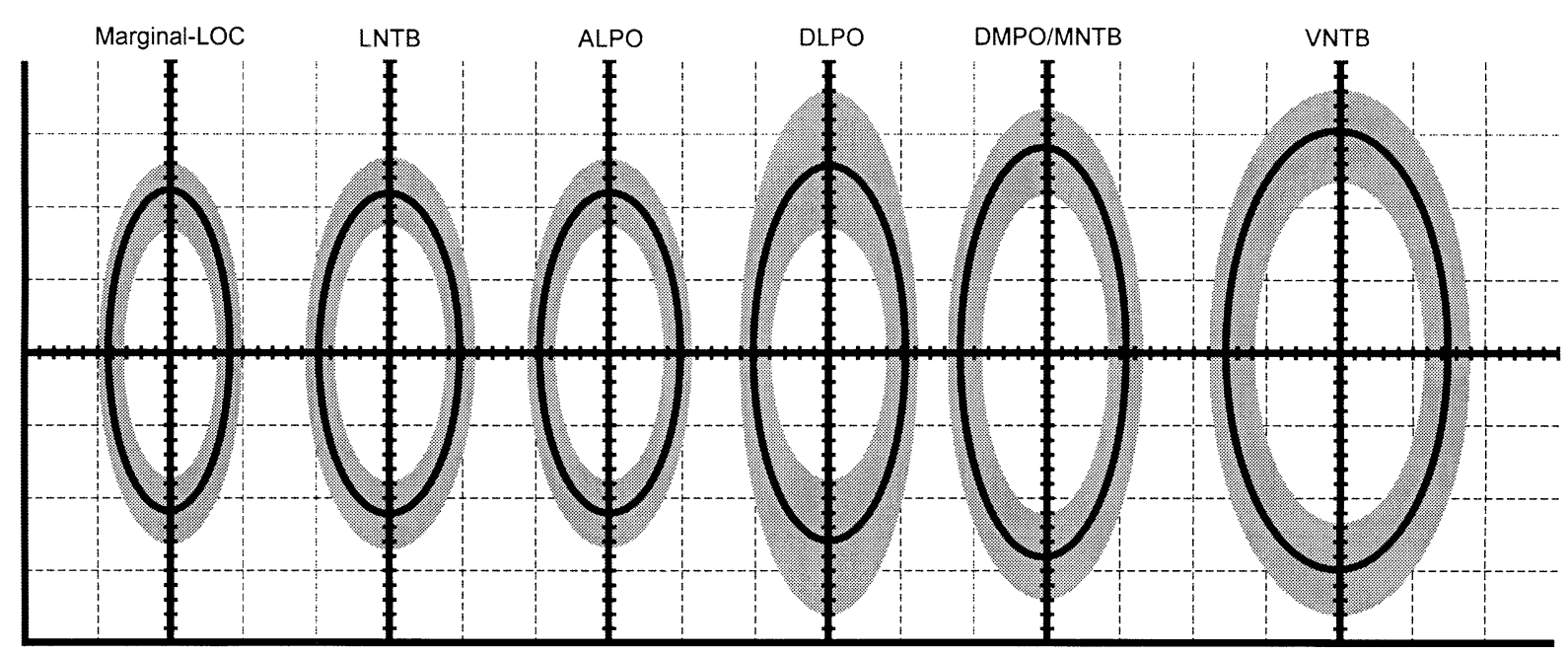

B. Frequency Distributions of Cell Body Areas, Including Means and SDs
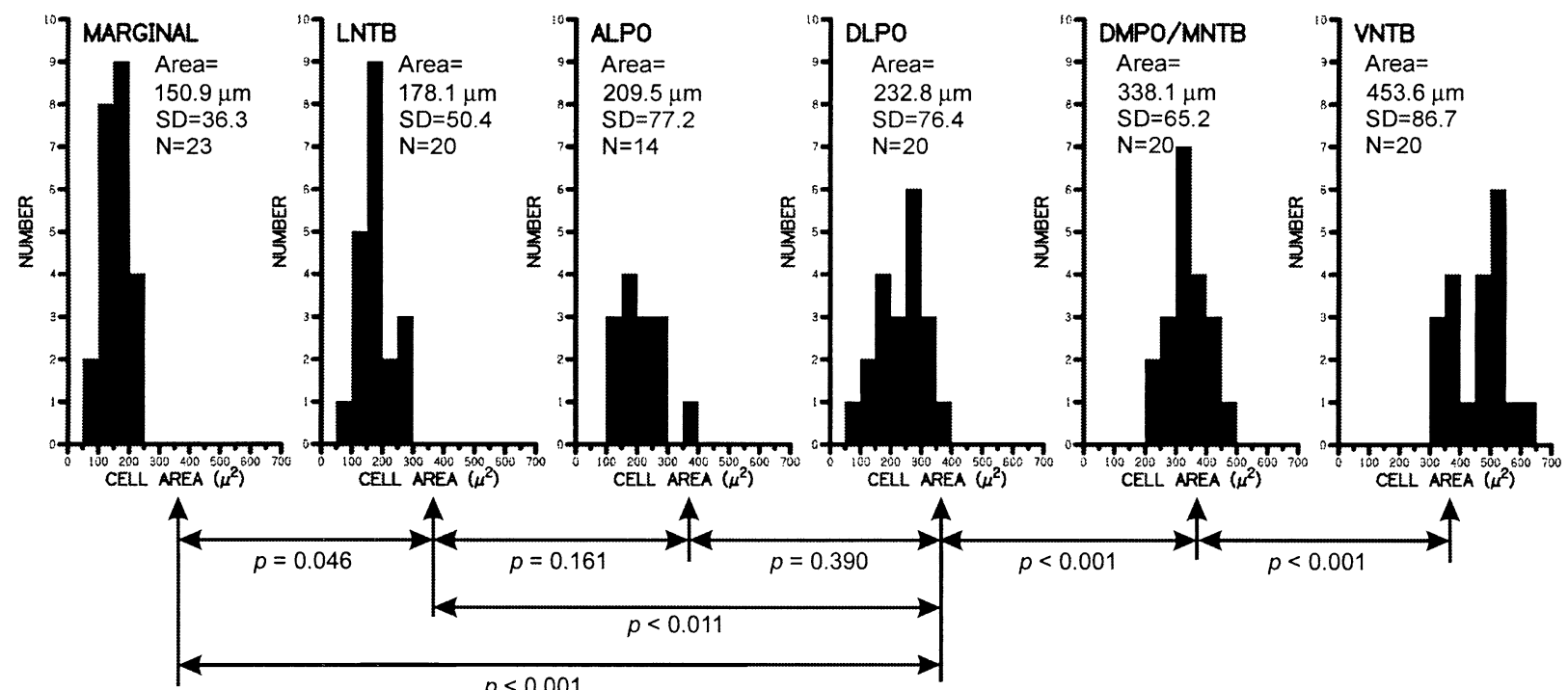

$p<0.001$

FIG. 9. A. Graphic representations (pictographs) of the average somatic size, shape, and standard deviation (SD) of neurons sampled from each OC cell group, based on their mean minimum (abscissa) and maximum (ordinate) diameters. The heavy elliptical line was generated using Matlab 6 software (The Mathworks, Inc. Natick, MA) to fit the mean minimum and maximum dimensions of each sample. The overlapping shaded ellipses represent one-half an SD plus and

their total number in every section, as well as the number of cells in each basic subgroup (marginal- vs. para-LOC neurons and DMPO/MNTB vs. VNTB) both ipsilaterally and contralaterally for each cat. A comparison of the resulting curves representing total LOC neurons (Figs. 5-7, A and B, circles) and MOC neurons (Figs. 5-7, $\mathrm{C}$ and $\mathrm{D}$, circles) reveals that the curves in corresponding panels for each cat have similar shapes, although individual variations do occur and are addressed below. With regard to total LOC neurons, the curves are similar in that they minus the mean. Tic marks on the axes represent $1 \mu \mathrm{m}$. The pictographs are arranged from left to right in order of increasing mean area, identical to the sequence used in B. The spacing between each pictograph is arbitrary and without significance B. Frequency histograms of somatic areas of neurons in each of the six samples. The mean area and SD for each sample is given on each graph. The $p$-values represent two-tailed $t$-tests between the populations indicated.

contain peaks in relation to midcaudorostral levels of the LSO bilaterally (Figs. 5-7, A and B). Similarly, peaks in total MOC neurons occur bilaterally in each cat in close relation to the rostral tip of MSO (Figs. 57, C and D). Thus, despite a large disparity in numbers between ipsilateral versus contralateral labeling of both LOC and MOC neurons, there are, nevertheless, discernible symmetries in the configurations of the plots of each group.

Ipsilaterally, marginal-LOC neurons exhibit a peak density of some 25-40 cells per section at midlevels of 


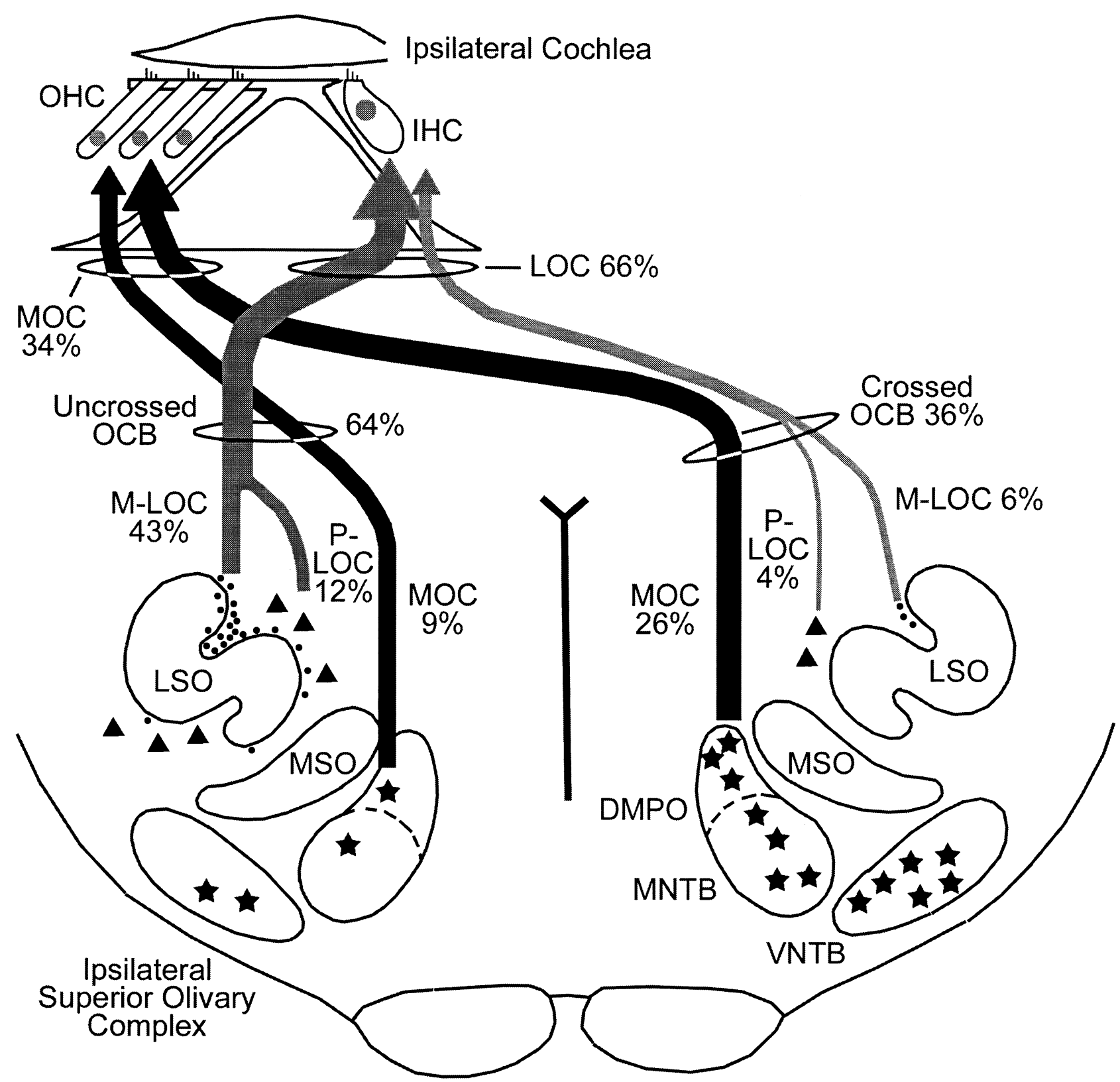

FIG. 10. Schematic diagram illustrating the origins of OC neurons innervating the left cochlea. The three types of neurons identified in this study are depicted by different symbols: $(\mathbf{O})$ marginal-LOC, $(\mathbf{\Delta})$ para-LOC, $(\star)$ MOC. The number and location of each type of symbol conveys its proportional contribution to the efferent inner-

the LSO, whereas contralaterally the peak density is only some 5-10 cells per section (Figs. 5-7, A and B, squares). There were troughs of various sizes in the ipsilateral plots, but across cats these were not consistent in caudorostral location. Regarding para-LOC neurons, the most consistent feature of their plots, which consist of the per-section sums of labeled neurons located in DLPO, LNTB, and ALPO, is the bilateral presence, of a peak near the rostral end of the LSO which extends several hundreds of micrometers beyond the rostral tip of this nucleus vation of the left cochlea. The percentages are based on the median values of each cell group in three cats (see Table 1, rightmost column). The terminations of the LOC and MOC systems shown are based on previous studies (Warr and Guinan 1979; Guinan et al. 1983). $100 \%$ OC neurons corresponds to 1570.

(Figs. 5-7, A and B, triangles). Cat Q86 is clearly exceptional in the magnitude of these peaks on each side (Fig. 5A, B), which are the result of an unusually large number of labeled neurons in ALPO (Table 1).

Regarding the distribution of MOC neurons, the cluster in the VNTB near the rostral end of the MSO has been noted in previous descriptions of the cat OC system (see Discussion) and was also a consistent feature of our data (Figs. 5-7, C and D). At its maximum, the number of cells per section in the VNTB (after smoothing) ranged from some 4-8 ipsilaterally 
to some 8-17, contralaterally. The plots of DMPO/ MNTB contralaterally also exhibit noticeable peaks at approximately the same caudorostral level as that in the corresponding VNTB, but only in cat Q86 was a peak found in DMPO/MNTB ipsilaterally. As a measure of the overall tendency of MOC neurons to cluster rostrally, we calculate that $75 \%$ of all MOC neurons were contained within the rostral-most $44 \%$ $49 \%$ or $40 \%-54 \%$ of their caudorostral range contralaterally and ipsilaterally, respectively.

Further comparison between the plots of DMPO/ MNTB and VNTB reveals that the latter are surprisingly sparse at levels corresponding to the caudal $50 \%-60 \%$ of the MSO and are quite consistently outnumbered there by cells in DMPO/MNTB (Figs. $5-7, \mathrm{C}$ and $\mathrm{D})$. This condition is dramatically reversed at the peak of MOC neuron concentration where VNTB cells consistently outnumber those in DMPO/ MNTB. At the rostral extremity of their range, a rough parity seems to prevail between the numbers of VNTB and DMPO/MNTB neurons (Figs. 5-7, C and D). A second feature revealed by the caudorostral plots is that, despite the smoothing procedure applied to the data, the MOC cell density (particularly in DMPO/MNTB) exhibits a periodicity suggesting that the cells are distributed in clusters rather than smoothly along the caudorostral extent of the SOC. This feature is particularly apparent on the contralateral side in all three plots (Figs. 5-7, D).

\section{Morphometric analysis of LOC and MOC neuronal somata}

Here we describe the results of measurements of neuronal soma size, shape, and area. Figure $8 \mathrm{~A}$ is a scatter plot of the minimum and maximum diameter of every soma measured in each of the six cell groups $(N=117)$. Although there is extensive overlap between the six populations in their linear dimensions, LOC neurons as a class (dots and triangles) tend to be smaller in both minimum and maximum diameter than MOC neurons (stars). This fact is clearer when the distributions of LOC and MOC neurons are plotted separately (Fig. 8B, C). Comparison of these two populations reveals that LOC and MOC neurons tend to cluster at different locations with respect to both axes. However, it is worth noting that several LOC neurons sampled from DLPO (filled triangles) are among the largest cells measured (Fig. 8B) and that quite a few of these cells overlap the distribution of MOC neurons (Fig. 8C). Regarding cell shape, the fact that both LOC and MOC neuronal populations are above the diagonal indicates that neurons belonging to both classes do not typically have circular somata but rather somewhat ovoid or even fusiform ones.
In order to visualize the average size and shape of cells in each of the six cell groups and to facilitate comparisons among them, we calculated the mean and standard deviation (SD) of the minimum and maximum diameters of each OC group and synthesized a pictograph of its size, shape, and dimensional variability (SD). As shown in Figure 9A, the resulting six pictographs readily fall into two groups based on size: one consisting of the three smaller pictographs to the left (marginal-LOC, LNTB, and ALPO) and the other consisting of the three larger pictographs to the right (DLPO, DMPO/MNTB, and VNTB). It appears that DLPO constitutes a distinctive population of LOC neurons in terms of size, even if its large variability, represented by the shaded elliptical band, may tend to exaggerate the apparent mean size of this population. In addition, a comparison of the pictographs of DMPO/MNTB and VNTB reveals, somewhat unexpectedly, a clear difference between them in both shape and apparent size.

Beneath the pictographs are found the corresponding frequency histograms of somatic areas, together with their respective means, SDs, and the $p$-values of two-tailed $t$-tests between different cell groups (Fig. 9B). Using a criterion of $p<0.005$ (Bonferroni correction), significant differences between LOC neuronal populations were found only between marginal-LOC neurons and para-LOC neurons in DLPO $(p<0.001)$ and ALPO $(p<0.003)$. DLPO also differed significantly from DMPO/MNTB neurons, as did the latter from VNTB, as indicated at the bottom of Figure 9B.

\section{Number of OC neurons}

Based on our counts in three cats, we found a mean total of $1607(\mathrm{SD}=70)$ OC neurons projecting to

FIG. 11. Comparisons between the present counts of OC neurons and those reported previously by Warr et al. (1982), Arnesen and Osen (1984), and Warren and Liberman (1989). A. Correlation between the number of LOC neurons (or unmyelinated axons) and MOC neurons (or myelinated axons) neurons in the present study and three previous reports (see key to Symbols). Each point represents a single specimen, except for the data of Warren and Liberman, where only means were available. Because LOC neurons were fewer than MOC neurons in cat 51 (594 and 914, respectively) in Warr et al. (1982), this case was plotted separately and not included in the correlation calculation or in the bar graph in B. B. Bar graph comparing the number and distribution of LOC and MOC neurons in the cat according to four studies. Note that the LOC and MOC neuronal data are plotted symmetrically around the midline. The mean numbers of myelinated and unmyelinated fibers were apportioned into ipsilateral and contralateral MOC and LOC neurons, respectively, using the mean ratios of ipsilateral/contralateral MOC and LOC neurons observed in the three retrograde labeling studies. Error bars for the VCA data are based on the SD for myelinated and unmyelinated fibers which were apportioned according to the size of each population. 


\section{A. Correlation between LOC and MOC Neurons}

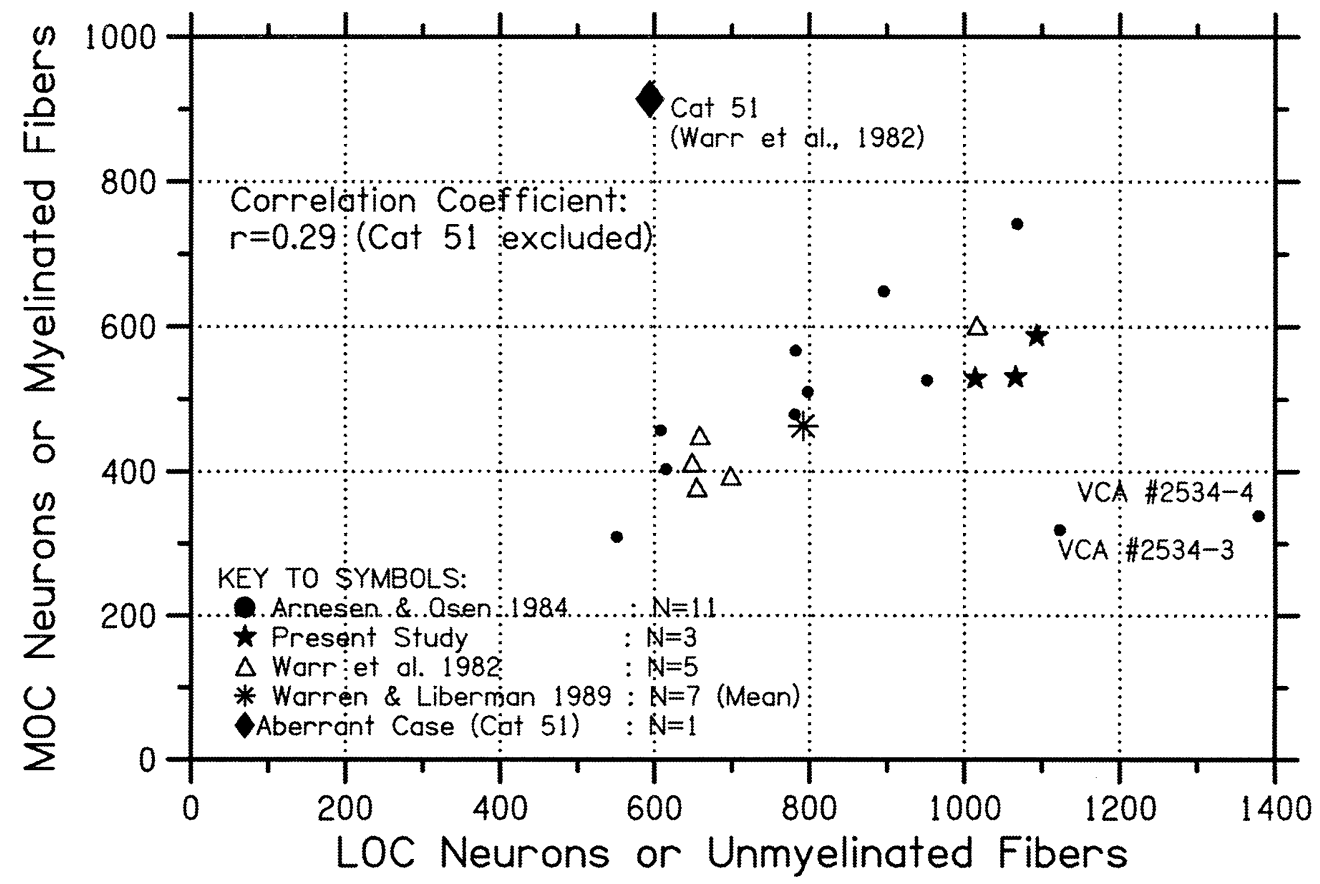

B. Four Estimates of the Distribution and Number of OC Neurons in the Cat

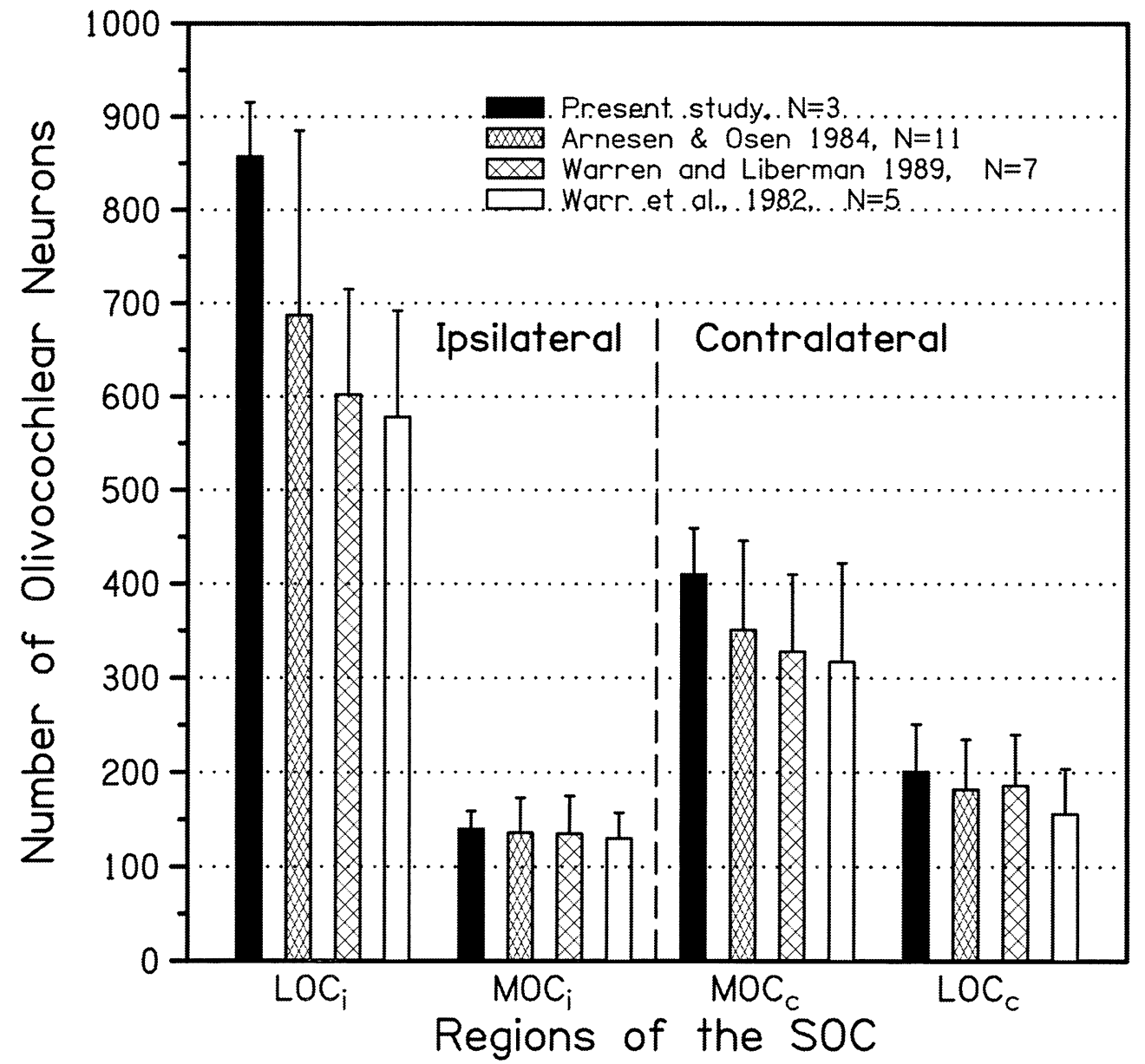


the left cochlea (see Group Data in Table 1). This total comprised mean totals of $1058(\mathrm{SD}=40)$ LOC neurons and $549 \quad(\mathrm{SD}=34)$ MOC neurons. The distribution of LOC and MOC neurons on each side, as well as their respective percentages of total $\mathrm{OC}$, confirm the previously observed pattern in which LOC neurons predominate ipsilaterally and MOC neurons predominate contralaterally. The relatively small SDs indicate the considerable stability of this pattern in the three cats we studied. The fact that the mean numbers of neurons, particularly LOC neurons, counted in this study are somewhat larger than previously reported is addressed in the Discussion.

Regarding the number and distribution of the two subgroups of LOC neurons, from Table 1 it can be calculated that marginal-LOC neurons have a mean total of $745(\mathrm{SD}=156)$ or $70 \%$ of all LOC neurons and para-LOC neurons have a mean total of $313(\mathrm{SD}=117)$ or $30 \%$. Although marginal-LOC neurons comprise an overwhelming majority of LOC neurons ipsilaterally, para-LOC neurons nevertheless are, on average, approximately a third as numerous (628/229 from Table 1). Contralaterally, the two groups are more nearly equal, but marginal-LOC neurons still comprise a majority (117/ 84).

Among the individual para-LOC subgroups, namely DLPO, LNTB, and ALPO, on average the single most populous of these on each side is DLPO and the least populous is ALPO (Table 1). However, it should be noted that the relatively large error bars for ALPO on each side are the result of unusually large numbers of neurons in this periolivary area in cat Q86, which we mentioned above. It should also be pointed out that, among para-LOC neurons, LNTB is unique in that labeling is virtually confined to the ipsilateral side.

Finally, Table 1 shows that, on average, the two MOC neuronal subgroups, DMPO/MNTB and VNTB, contain more or less equal numbers of neurons, which is perhaps unexpected in view of the dense cluster of VNTB cells occurring contralaterally. However, the abundance of these cells rostrally is compensated by their relative paucity in the caudal two-thirds of the SOC, as described above.

In order to conveniently summarize these numerical data, we have constructed a schematic diagram of the cat's SOC that illustrates the location and percentage of neurons in the three groups of OC neurons on each side that project to the left cochlea (Fig. 10). We based the diagram on median values found in the three cats rather than means in order to lessen the impact of any aberrant counts in individual cats (see footnote to Table 1).

\section{DISCUSSION}

\section{Main results}

We have carried out a comprehensive examination of the OC neurons in the cat using CTB as a retrograde tracer. The findings provide new insights concerning (1) the distribution and number of OC neurons, (2) the division of LOC neurons into two subgroups, (3) the caudorostral distribution of LOC and MOC neurons, and (4) differences in morphology among neurons comprising the various cell groups of the LOC and MOC systems.

\section{Advantages of CTB as a retrograde marker}

Our observations regarding CTB fully confirm the exceptional sensitivity of this marker, as originally described by Ericson and Blomqvist (1988). They also confirm the power of CTB to reveal morphological details of OC neurons, as previously demonstrated in the rat (Vetter and Mugnaini 1992) and cat (Ye et al. 2000a). We found that CTB had two key advantages over HRP demonstrated with tetramethylbenzidine: an absence of crystalline artifacts at sites of labeling and a low level of background staining. These properties allowed us to confidently delineate labeled somata in order to either count them or make measurements of their length and width. The possible effects of the increased sensitivity of CTB on the number of labeled neurons observed in our material is addressed below.

\section{Number of OC neurons and comparison with other studies}

In order to evaluate the counts of LOC and MOC we obtained with CTB, it is instructive to compare them with numerical data reported in previous studies. We have identified three studies in the cat, two using retrograde labeling with HRP (Warr et al. 1982; Warren and Liberman 1989) and one involving counts of myelinated and unmyelinated axons in the vestibulo-cochlear anastomosis (VCA) (Arnesen and Osen 1984), with which our data can be compared, and we have plotted these data together in ure $11 \mathrm{~A}$ and $\mathrm{B}$.

The scatter plot in Figure 11A illustrates the correlation between both the number of LOC and MOC neurons labeled by retrograde transport and the number of unmyelinated and myelinated axons, respectively, found in each VCA, the latter as already noted by Arnesen and Osen (1984). Because we included two aberrant cases reported by Arnesen and Osen (1984) (see far right in the graph in Fig. 11A), the correlation coefficient of these pooled data was a 
relatively weak $r=0.29$; however, if these two cases are excluded, $r$ increases to 0.82 .

The results of retrograde labeling studies thus confirm those based on axon counts, indicating that, typically, animals with a large number of one type of element also tend to have a large number of the other, although exceptional cases do occur. This plot also shows that the three cats of the present study (stars), although arguably a part of the elongated cluster formed by all the typical cases plotted, nevertheless occupy the extreme upper end of the range of LOC neurons and are also above the median with respect to the number of labeled MOC neurons.

This point is further illustrated in the bar graph in Figure 11B, where the mean total numbers of LOC and MOC neurons from the four studies are separated according to their actual or, in the case of VCA axon counts, their estimated distribution ipsilaterally or contralaterally (see caption). This plot is striking in that the mean number of ipsilateral LOC neurons obtained with CTB is significantly larger than either that obtained with HRP or as estimated to be present in the average VCA; however, a correspondingly large number of LOC is not apparent contralaterally. In contrast, the numbers of MOC ipsilaterally and contralaterally are quite similar across the four experiments.

While it is perhaps tempting to attribute the large number LOC neurons in our cats to the efficiency of CTB as a retrograde marker, there are several reasons why drawing such a conclusion might prove to be premature. First, it may be that LOC populations in the small sample of cats we examined were atypical or, second, that we may have simply overcounted these small neurons. With regard to the latter, however, we used procedures designed to minimize overcounting and note that this same counting technique was employed in Warr et al. (1982) without producing unusually high counts of LOC neurons compared with those of Warren and Liberman (1989), who employed similar HRP labeling techniques (Fig. 11A). Third, if the greater sensitivity of CTB explains the higher counts of LOC neurons, how is it that this advantage was found only ipsilaterally? Finally, since the VCA appears to provide the sole route by which olivocochlear axons reach the organ of Corti in mature animals (Rasmussen 1953; Bruce et al. 1997), the number of unmyelinated axons there presumably affords the best estimate of the total number of LOC reaching a given cochlea, although one should perhaps allow for the possibility that some of these extremely thin axons might have escaped even the most scrupulous effort to count them. In sum, we believe that the question of whether our higher counts of LOC neurons represents a more accurate estimate of this population than provided by previous studies remains unanswered.

\section{Two types of LOC neurons}

Based on previous studies in the cat employing either cholinergic markers (Osen and Roth 1969; Osen et al. 1984; Vincent and Reiner 1987), retrograde labeling (Adams 1983; Warr et al. 1986), or a combination of the two (Warr 1975), it was clear that the great majority of cochlear efferent neurons in the lateral periolivary region were marginal-LOC neurons. However, these studies provided only fragmentary information about the other LOC neurons which were situated at some distance from the LSO. The median total of LOC neurons in the present study was 1029, of which $733(75 \%)$ were marginal-LOC and the remaining 256 (25\%) were para-LOC neurons. Ipsilaterally, DLPO and LNTB together number nearly 200 neurons, and, contralaterally, DLPO and ALPO contain about 60 neurons (Fig. 10).

Compared to the rat, the cat would appear to have a relatively larger percentage of para-LOC than is comprised by shell neurons which surround the LSO in the rat. Specifically, it has been reported that shell neurons in the rat comprise some $12 \%$ (Horvath et al. 2000) to $15 \%$ of all LOC (Vetter and Mugnaini 1992), the latter estimate being based on retrograde labeling with CTB. On the other hand, the guinea pig is estimated to have only $6 \%-9 \%$ of neurons innervating the IHC which provide bidirectional (shell-like) innervation (Brown 1987).

The distinction between marginal-LOC and paraLOC neurons, although based on differences in proximity to the LSO, in fact rests on the previously demonstrated immunoreactivity of marginal-LOC neurons to antibodies against CGRP (Lu et al. 1987). Based on their detailed description (Lu et al. 1987, Fig. 2), it appears that scarcely any CGRP + cells lacked intimate contact with the LSO, which would exclude para-LOC neurons as defined here. This neurochemical difference between marginal-LOC and para-LOC neurons suggests that they comprise functionally distinct subgroups and argues against the notion that para-LOC neurons might consist merely of ectopic marginal-LOC neurons. If the latter idea were valid, the numbers of para-LOC neurons on each side should be proportional to the corresponding numbers of marginal-LOC neurons. Ipsilaterally, however, para-LOC neurons comprise a much smaller proportion (22\% in terms of median numbers of neurons) of LOC neurons than contralaterally (42\%), as can be derived from Table 1. Furthermore, the ectopic explanation of para-LOC neurons is difficult to reconcile with the fact that LNTB was labeled 
only ipsilaterally, whereas marginal-LOC neurons are labeled bilaterally.

\section{Morphometry of LOC neurons}

The present measurements indicate that marginalLOC neurons were quite uniformly the smallest of any of the LOC cell groups; however $p$-values of less than 0.005 were obtained only in $t$-tests between marginal-LOC and the para-LOC neurons of DLPO and ALPO.

The question of soma size appears to be important because in the rat, the large shell neurons, with a mean major diameter of $25 \mu \mathrm{m}$ (Vetter and Mugnaini 1992), are known to be the source of a longitudinally diffuse innervation beneath the IHC, whereas intrinsic LOC neurons, with an average diameter of $13 \mu \mathrm{m}$, supply a more focal innervation to the same region (Warr et al. 1997). It may be that the large soma of shell neurons is an adaptation related to their extensive axon, which, although thin, gives off several branches within the intraganglionic spiral bundle, each of which branches again into long, basally and apically coursing fibers in the inner spiral bundle, each of which forms a large number of varicosities (Brown 1987; Warr et al. 1997). It is therefore natural to hypothesize that, if a longitudinally diffuse efferent innervation exists in the IHC region of the cat's organ of Corti, the larger cells in the DLPO and ALPO are its most likely source. Of course, such a conjecture leaves open the question of what morphological specialization(s), if any, the smaller para-LOC neurons of DLPO, LNTB, and ALPO might have beneath the IHC.

\section{Comparative studies of LOC neurons}

Studies in several other species also suggest that differences in cell size and location among LOC neurons is not limited to the rat and cat. Thus, large and small LOC neurons have been described in the guinea pig (Robertson et al. 1987), squirrel monkey (Thompson and Thompson 1986), chinchilla (Azeredo et al. 1999), and, on the basis of ChAT immunocytochemistry, in humans (Moore et al. 1999). In the gerbil, small LOC neurons within the LSO and large neurons outside the LSO differ in their selective retrograde transport, respectively, of D-aspartic acid (Ryan et al. 1987) and nipecotic acid (Ryan et al. 1992).

\section{Concentration of MOC neurons in the rostral SOC}

The presence of a major cluster of large MOC neurons situated rostrally in the VNTB has been reported in several previous studies in the cat based on AChE histochemistry (Osen and Roth 1969; Guinan et al. 1983; Osen et al. 1984), retrograde labeling (Adams
1983; Warr et al. 1986), and a combination of the two (Warr 1975). Our observations confirm this as a reliable feature of the VNTB, not only contralaterally but ipsilaterally as well. Furthermore, based on the extensive retrograde filling of dendrites obtained with CTB, we also noted for the first time that extensive dendritic intertwining occurs in the rostral VNTB (Fig. 4F). One might predict on the basis of this characteristic that afferent inputs to MOC neurons, which often contact their long dendrites (Thompson and Thompson 1991, 1993; Ye et al. 2000a), would be likely to recruit activity in clusters of these cells, rather than selectively or in isolated neurons.

The caudorostral plots also reveal a modest peak in the number of cells in the contralateral DMPO/MNTB which was also situated near the rostral end of the MSO, but its location did not necessarily coincide precisely with the corresponding peak in the VNTB. The existence of a peak in DMPO/MNTB on the ipsilateral side was not consistent among the three cats.

Although the presence of a cluster of MOC neurons in the rostral VNTB of the cat has been known for some time, we are unaware of any hypotheses relating to its possible functional significance. For example, a comprehensive examination of the efferent projections to the cochlea from various sites in DMPO, MNTB, and VNTB, including the major cluster in rostral VNTB, did not reveal any fundamental differences in kind between injection sites, except that more dorsal injections projected more basally in both cochleas than did more ventral injections (Guinan et al. 1983, 1984).

Two previously unreported features of the distribution of MOC neurons were observed in all three cats. First, VNTB neurons were surprisingly sparse at levels corresponding to the caudal $50 \%-60 \%$ of the MSO, bilaterally, where they were consistently outnumbered by cells in DMPO/MNTB. Second, the plots of DMPO/MNTB neurons exhibit a consistent, although somewhat irregular, undulatory form, which is indicative of neuronal clustering. Although some tendency toward undulation can also be found in the caudorostral plots of VNTB neurons, it was not as clear as that observed in the plots of DMPO/MNTB neurons. Interestingly, undulation can be seen in caudorostral plots of MOC neurons in other species, including the chinchilla (Azeredo et al. 1999), guinea pig, and rat (Aschoff and Ostwald 1987), but the phenomenon had not been specifically noted or discussed in these earlier studies.

\section{Rostral concentration of MOC neurons in other species}

Information on the caudorostral distribution of MOC neurons has been published for several species other 
than cat, including the chinchilla (Azeredo et al. 1999), hamster (Simmons et al. 1999), rat (Aschoff and Ostwald 1987), mouse (Campbell and Henson 1988), guinea pig (Aschoff and Ostwald 1987), squirrel monkey (Thompson and Thompson 1986), several species of gerbil (Aschoff et al. 1988), and three species of bats: Pteronotis (Bishop and Henson 1987), Rhinopoma, and Tadarida (Aschoff and Ostwald 1987). Ignoring for the moment the fact that, across species, MOC neurons exhibit a range of different dorsoventral periolivary locations, many animals nevertheless exhibit a well-defined peak in MOC neuron density at the rostral end of the SOC. However, several species do not. Specifically, in the chinchilla, the distributions are rather flat bilaterally and may actually have slightly more cells in the caudal half of the SOC than in the rostral half. In the bats Pteronotis and Rhinopoma, the peak is situated at the caudal end of the SOC and rostrally the number of MOC neurons declines rapidly to zero. We are unaware of any hypotheses that might account for these differences.

\section{Morphometry of MOC}

A morphometric analysis of MOC neurons indicated that, as a group, VNTB neurons are slightly larger (45 $\mu \mathrm{m}^{2}$ ) and less elongated than those in DMPO/MNTB $\left(338 \mu \mathrm{m}^{2}\right)$, a difference that had not been previously reported in the cat. When we applied a $t$-test to the somatic area data, it was found that the mean for VNTB neurons was significantly larger than the mean for neurons in DMPO/MNTB $(p<0.001)$, although comparison of the area histograms for the two populations shows that they overlap considerably. In the squirrel monkey, somewhat more dramatic differences in size have been reported: VNTB neurons were found to have a mean area of $308 \mu \mathrm{m}^{2}$ compared with those in DMPO which averaged only $182 \mu \mathrm{m}^{2}$ (Thompson et al. 1985).

\section{ACKNOWLEDGMENTS}

We wish to thank the following: Duarte Machado (UCHC) for assistance in conducting the experiments on cats and histological processing of the tissue; Skip Kennedy, Media Graphics Specialist (BTNRH), for producing the drawings and illustrations; Denis Fitzpatrick (BTNRH) for creating the pictographs in Figure 9; and Barbara Olmedo and Charlotte Lieser for their generous help in formatting the manuscript. Supported by NIH Grant NIDCD DC00215 (WBW) and DC00360 (DOK).

\section{REFERENCES}

ADAMs JC. Cytology of periolivary cells and the organization of their projections in cat. J. Comp. Neurol. 215:275-289, 1983.
ARnesen AR, Osen KK. Fibre population of the vestibulocochlear anastomosis in the cat. Acta Otolaryngol. (Stockh.) 98:255-269, 1984.

Aschoff A, Muller M, Отт H. Origin of cochlear efferents in some gerbil species. Exp. Brain Res. 71:252-262, 1988.

Aschoff A, Ostwald J. Different origins of cochlear efferents in some bat species, rats, and guinea pigs. J. Comp. Neurol. 264:56-72, 1987.

Azeredo WJ, Kliment ML, Morley BJ, Relkin E, Slepecky NB, Sterns A, Warr WB, WeEkly JM, Woods CI. Olivocochlear neurons in the chinchilla: a retrograde fluorescent labelling study. Hear. Res. 134:57-70, 1999.

Bishop AL, Henson OWJ. The efferent cochlear projections of the superior olivary complex in the mustached bat. Hear. Res. 31:175-182, 1987.

Bodian D. A new method for staining nerve fibers and nerve endings in mounted paraffin sections. Anat. Rec. 65:89-95, 1936.

BRown MC. Morphology of labeled efferent fibers in the guinea pig cochlea. J. Comp. Neurol. 260:605-618, 1987.

BRown MC. Fiber pathways and branching patterns of biocytin-labeled olivocochlear neurons in the mouse brainstem. J. Comp. Neurol. 337:600-613, 1993.

Bruce LL, Kingsley, J, Nichols DH, Fritzch B. The development of vestibulocochlear efferents and cochlear afferents in mice. Int. J. Dev. Neurosci. 15:671-692, 1997.

Campbell JP, Henson MM. Olivocochlear neurons in the brainstem of the mouse. Hear. Res. 35:271-274, 1988.

Coggeshall RE, LeKAN HA. Methods for determining numbers of cells and synapses: a case for more uniform standards of review. J Comp. Neurol. 364:6-15, 1996 [Published erratum appears in J. Comp. Neurol 369:162, 1996].

Dechesne C, Raymond J, SAns A. The efferent vestibular system in the cat: a horseradish peroxidase and fluorescent retrograde tracers study. Neuroscience 11:893-901, 1984.

ERICSON H, BlomQVist A. Tracing of neuronal connections with cholera toxin subunit B: light and electron microscopic immunohistochemistry using monoclonal antibodies. J. Neurosci. Meth. 24:225-235, 1988.

GACEK RR, LYON M. The localization of vestibular efferent neurons in the kitten with horseradish peroxidase. Acta Otolaryngol. 77:92-101, 1974.

GinzBERG RD, Morest DK. Fine structure of cochlear innervation in the cat. Hear. Res. 14:109-127, 1984.

GUINAN JJ, WARR WB, NORRIS BE. Differential olivocochlear projections from lateral versus medial zones of the superior olivary complex. J. Comp. Neurol. 221:358-373, 1983.

GuINAN JJ, WARR WB, NORRIS BE. Topographic organization of the olivocochlear projections from the lateral and medial zones of the superior olivary complex. J. Comp. Neurol. 226:21-27, 1984.

Horvatb M, Kraus KS, Illing RB. Olivocochlear neurons sending axon collaterals into the ventral cochlear nucleus of the rat. J Comp. Neurol. 422:95-105, 2000.

Ito J, Takahashi H, Matsuoka I, Takatani T, Sasa M, Takaori S. Vestibular efferent fibers to ampulla of anterior, lateral and posterior semicircular canals in cats. Brain Res. 259:293-297, 1983.

Joseph MP, Guinan JJ, Fullerton BC, Norris BE, Kiang NYS. Number and dustribution of stapedius motoneurons in cats. J. Comp Neurol. 232:43-54, 1985.

Kawai Y, Takami K, Shiosaka S, Emson PC, Hillyard CJ, Girgis S, MacIntyre I, TOHYAma M. Topographic localization of calcitonin gene-related peptide in the rat brain: an immunohistochemical analysis. Neuroscience 15:747-763, 1985.

Kimura RS, Wersall J. Termination of the olivocochlear bundle in relation to the outer hair cells of the organ of Corti in guinea pig. Acta Otolaryngol. (Stockh.) 55:11-32, 1962.

Liberman MC. Efferent synapses in the inner hair cell area of the cat cochlea: An electron microscopic study of serial sections. Hear. Res. 3:189-204, 1980. 
Liberman MC. The cochlear frequency map for the cat: Labeling auditory-nerve fibers of known characteristic frequency. J. Acoust. Soc. Am. 72:1441-1449, 1982.

Liberman MC, Dodds LW, Pierce S. Afferent and efferent innervation of the cat cochlea: Quantitative analysis with light and electron microscopy. J. Comp. Neurol. 301:443-460, 1990.

Lu SM, Schweitzer L, Cant NB, Dawbarn D. Immunoreactivity to calcitonin gene-related peptide in the superior olivary complex and cochlea of cat and rat. Hear. Res. 31:137-146, 1987.

Mathisen JS, Blackstad TW. Cholinesterase in the hippocampal region. Distribution and relation to architectonics and afferent systems. Acta Anat. (Basel) 56:216-253, 1964.

Moore JK, Simmons DD, GuAN Y. The human olivocochlear system: organization and development. Audiol. Neurootol. 4:311-325, 1999.

Osen KK, Mugnaini E, Dahl AL, Christiansen AH. Histochemical localization of acetylcholinesterase in the cochlear and superior olivary nuclei. A reappraisal with emphasis on the cochlear granule cells system. Arch. Ital. Biol. 122:169-212, 1984.

Osen KK, Rотн K. Histochemical localization of cholinesterases in the cochlear nuclei of the cat, with notes on the origin of acetylcholinesterase-positive afferents and the superior olive. Brain Res. 16:165-185, 1969.

RASMUSSEN GL. Further observations on the efferent cochlear bundle. J. Comp. Neurol. 99:61-74, 1953.

Robertson D, Cole KS, Harvey AR. Brainstem organization of efferent projections to the guinea pig cochlea studied using the fluorescent tracers fast blue and diamidino yellow. Exp. Brain Res. 66:449-457, 1987.

Ryan AF, Schwartz IR, Helfert RH, Keithley E, Wang ZX. Selective retrograde labeling of lateral olivocochlear neurons in the brainstem based on preferential uptake of 3H-D-aspartic acid in the cochlea. J. Comp. Neurol. 255:606-616, 1987.

Ryan AF, Schwartz IR, Keithley EM, Wang ZX. Selective retrograde transport of nipecotic acid, a GABA analog, labels a subpopulation of gerbil olivocochlear neurons. J. Comp. Neurol. 326: 337-346, 1992.

SAndo I. The anatomical interrelationships of the cochlear nerve fibers. Acta Otolaryngol. 59:417-436, 1965.

SAtake M, Liberman MC. Morphological subclasses of lateral olivocochlear terminals? Ultrastructural analysis of inner spiral bundle in cat and guinea pig. J. Comp. Neurol. 371:621-632, 1996.

Shaw MD, Baker R. The locations of stapedius and tensor tympani motoneurons in the cat. J. Comp. Neurol. 216:10-19, 1983.

Simmons DD, Bertolotto C, Typpo K, Clay A, Wu M. Differential development of cholinergic-like neurons in the superior olive: a light microscopic study. Anat. Embryol. (Berl.) 200:585-595, 1999.

Sмiтh CA. Innervation pattern of the cochlea. The internal hair cell. Ann. Otol. Rhinol. Laryngol. 70:504-527, 1961.

SPIROU GA, BERREBI AS. Organization of ventrolateral periolivary cells of the cat superior olive as revealed by PEP-19 immunocytochemistry and Nissl stain. J. Comp. Neurol. 368:100-120, 1996.

Spoendin H. The organization of the cochlear receptor. Adv. Otorhinolaryngol. 13:1-227, 1966.

Thompson AM, Thompson GC. Posteroventral cochlear nucleus projections to olivocochlear neurons. J. Comp. Neurol. 303: 267-285, 1991.

Thompson AM. Heterogeneous projections of the cat posteroventral cochlear nucleus. J. Comp. Neurol. 390:439-453. 1998.
Thompson AM, Thompson GC. Relationship of descending inferior colliculus projections to olivocochlear neurons. J. Comp. Neurol. 335:402-412, 1993.

Thompson GC, Igarashi M, Stach BA. Identification of stapedius muscle motoneurons in squirrel monkey and bush baby. J. Comp. Neurol. 231:270-279, 1985.

Thompson GC, Thompson AM. Olivocochlear neurons in the squirrel monkey brainstem. J. Comp. Neurol. 254:246-258, 1986.

Tsuchitani C, Boudreau JC. Single unit analysis of cat superior olive S-segment with tonal stimuli. J. Neurophysiol. 47:479-500, 1966.

Vetter DE, Adams JC, Mugnaini E. Chemically distinct rat olivocochlear neurons. Synapse 7:21-43, 1991.

Vetter DE, Mugnaini E. Distribution and dendritic features of three groups of rat olivocochlear neurons. A study with two retrograde cholera toxin tracers. Anat. Embryol. (Berl.) 185: 1-16, 1992.

Vincent SR, Reiner PB. The immunohistochemical localization of choline acetyltransferase in the cat brain. Brain Res. Bull. 18: 371-415, 1987.

WARR WB. Olivocochlear and vestibular efferent neurons of the feline brain stem: their location, morphology and number determined by retrograde axonal transport and acetylcholinesterase histochemistry. J. Comp. Neurol. 161:159-182, 1975.

WARR WB. Organization of olivocochlear efferent systems in mammals. In: Webster DB, Popper AN, Fay RR, (eds) The Mammalian Auditory Pathway: Neuroanatomy. New York, SpringerVerlag, pp. 410-448, 1992.

WARR WB, Beck Boche J, NeEly ST. Efferent innervation of the inner hair cell region: Origins and terminations of two lateral olivocochlear systems. Hear. Res. 108:89-111, 1997.

WARR WB, Boche JE, Ye Y, KIM DO. Distribution and number of two types of lateral olivocochlear neurons (LOC) in the cat. Abstr. Assoc. Res. Otolaryngol. 24:47, 2001.

WARR WB, GUINAN JJ. Efferent innervation of the organ of Corti: two separate systems. Brain Res. 173:152-155, 1979.

WARR WB, Guinan JJ, White JS. Organization of the efferent fibers: The lateral and medial olivocochlear systems. In: Altschuler RA, Hoffman DW, Bobbin RP, (eds) Neurobiology of Hearing: The Cochlea. New York, Raven Press, pp. 333-348, 1986.

WARR WB, White JS, NyFfeler MJ. Olivocochlear neurons: Quantitative comparison of the lateral and medial efferent systems in adult and newborn cats. Soc. Neurosci. Abstr. 8:346, 1982.

WARR WB, YE Y, Boche JE, KIM DO. Olivocochlear neurons in the cat: Possible homologues of rodent shell and intrinsic neurons revealed by retrograde transport of cholera toxin-B. Abstr. Assoc. Res. Otolaryngol. 23:134, 2000.

WARREN EH, Liberman MC. Effects of contralateral sound of auditory-nerve responses. I. Contributions of cochlear efferents. Hear. Res. 37:89-104, 1989.

Wilson JL, Henson MM, Henson OW. Course and distribution of efferent fibers in the cochlea of the mouse. Hear. Res. 55:98108, 1991.

Ye Y, Machado DG, Kim DO. Projection of the marginal shell of the anteroventral cochlear nucleus to olivocochlear neurons in the cat. J. Comp. Neurol. 420:127-138, 2000a.

YE Y, WARr WB, Boche JE, KIM DO. The marginal shell of the cat ventral cochlear nucleus revealed by axonal terminal fields labeled with cholera toxin subunit-B. Abstr. Assoc. Res. Otolaryngol. 23:38, 2000b. 